\title{
Triaxial Creep Behavior of Red Sandstone in Freeze- Thaw Environments
}

\author{
Yongjun Song, Yongxin Che $\mathbb{D}^{D}$, Leitao Zhang ${ }^{D}$, Jianxi Ren, Shaojie Chen, and Mengling Hu \\ College of Architecture and Civil Engineering, Xi'an University of Science and Technology, Xi'an 710054, China \\ Correspondence should be addressed to Leitao Zhang; zhanglt95@163.com
}

Received 7 October 2020; Revised 19 November 2020; Accepted 23 November 2020; Published 29 December 2020

Academic Editor: Yanlin Zhao and Yanlin Zhao

Copyright (C) 2020 Yongjun Song et al. This is an open access article distributed under the Creative Commons Attribution License, which permits unrestricted use, distribution, and reproduction in any medium, provided the original work is properly cited.

\begin{abstract}
To investigate the time-dependent mechanical properties of rock masses in cold regions under the effects of freeze-thaw cycling and long-term loading, triaxial multilevel loading and unloading creep tests were performed on saturated red sandstone samples subjected to different numbers of freeze-thaw cycles. The effects of freeze-thaw cycles and confining pressure on the creep properties, long-term strength, and creep failure mode of the rock were analyzed. The effect of freeze-thaw cycles on the microstructure of the rock was analyzed using scanning electron microscopy. The results showed that as the number of freezethaw cycles increased, the rock particle boundaries became more distinct, and more pores formed. The effect of freeze-thaw cycles on the creep deformation of red sandstone was related to the loading stress level. At low stress levels, the rock viscoelastic strain increased gradually and almost linearly with an increasing number of freeze-thaw cycles; in contrast, at high stress levels, the rock viscoelastic strain increased nonlinearly. The viscoplastic strain increased almost linearly with increasing freeze-thaw cycles. The fourth loading stress level $\left(70 \% \sigma_{c}\right)$ corresponded to the transition of the creep deformation of the red sandstone. When the confining pressure was low, a higher stress level caused the confining pressure to have a more significant effect on the creep strain. However, as the confining pressure continued to increase, the effect of the confining pressure on the creep strain eventually disappeared. The long-term strength of the red sandstone decreased approximately linearly with an increase in the number of freeze-thaw cycles. When the number of freeze-thaw cycles and the confining pressure were high, the rock samples formed a transverse shear plane and were more fragmented than those without a transverse shear plane. These results provide a reference for construction in rock mass engineering and long-term stability analysis in cold regions.
\end{abstract}

\section{Introduction}

In cold regions, rock masses are subjected to the combined effects of freeze-thaw cycles and external loads. When investigating freeze-thaw disasters, it is also necessary to examine the creep behavior and strength reduction caused by longterm external loads. Therefore, the study of rock creep behavior in a freeze-thaw environment is crucial for rock mass engineering in cold regions. With increased human activity, large-scale rock mass construction projects, such as cold area tunnels, highways, and slope engineering projects, have commenced in cold regions. However, tunnels, roadbeds, and slopes in cold regions experience varying degrees of frostheave cracking, freeze-thaw slumping, supporting structure instability, leakage, and freezing damage owing to longterm seasonal changes and significant day-night temperature variations because of the complex geographical environment and climatic conditions, such as seasonal frozen soil in plateau alpine regions.

In recent years, several scholars have conducted studies on the mechanical properties of rocks and the damage induced within them under freeze-thaw conditions. Yamabe and Neaupane [1] performed uniaxial compression tests on a rock sample after subjecting it to freeze-thaw cycling and found that its uniaxial compressive strength increased with decreasing temperature but decreased with an increasing number of freeze-thaw cycles. Chen et al. [2] conducted freeze-thaw cycle tests on tuff with varying water content and reported that freeze-thaw cycling had a minimal effect on the rock strength when the water content was below $60 \%$ but that the rock strength significantly decreased due to freeze-thaw cycling when the water content exceeded 
70\%. Yavuz et al. [3] carried out experimental tests to determine the freeze-thaw damage evolution of 12 types of carbonate rocks and observed that the wave velocity, hardness, and compressive strength of the rock samples after being subjected to freeze-thaw cycles decreased to varying degrees. Zhang and Yang [4] considered the coupling effect of freezethaw cycling and loading; proposed the concepts of freezethaw damage, loaded damage, and total damage; and established a freeze-thaw loading damage model of rocks. Bayram [5] investigated the strength development of nine types of limestone from Turkey subjected to varying numbers of freeze-thaw cycles. Khanlari et al. [6] and Momeni et al. [7] performed freeze-thaw cycle and uniaxial compression tests on different types of rocks and determined the effects of freeze-thaw cycles on $\mathrm{P}$ wave velocity, strength, and porosity. Liping et al. [8] determined the physical parameters and triaxial-compression mechanical properties of coarse and fine sandstones subjected to different numbers of freezethaw cycles. Their results showed that intact hard rocks exhibited significant attenuation effects under freeze-thaw conditions. Seyed Mousavi et al. [9] and Zhao et al. [10] conducted compression tests on rocks after subjecting them to freeze-thaw cycles, investigated the effects of freeze-thaw cycles on the rock compressive strength, and analyzed the effects of freeze-thaw conditions on rock microstructures using scanning electron microscopy (SEM). Lu et al. [11] carried out freeze-thaw cycle tests and triaxial compression tests on four cases of flawed sandstone to analyze the influence of freeze-thaw cycling on the mechanical properties of the rocks and propose an equation to describe the loading-induced damage evolution of sandstone that previously underwent freeze-thaw cycling. Some researchers placed sandstone samples in different chemical solutions when performing freezethaw cycle tests to analyze the effects of these chemical solutions on the freeze-thaw damage relationships and mechanical properties of the sandstone [12-16].

The studies mentioned above investigated the mechanical properties and damage mechanism of rocks subjected to freeze-thaw conditions and reported various research results. However, under actual conditions, rock masses are often subjected to long-term effects of the surrounding rock pressure and other loads, and the creep behavior of rocks under long-term loading is a critical factor that affects their longterm stability and can cause rock damage [17-21]. Therefore, it is necessary to study the creep behavior of rocks in freezethaw environments. Currently, several scholars have investigated the creep characteristics and damage mechanisms of rocks under long-term loading [22-28]; however, the creep behavior of rocks in a freeze-thaw environment has not been studied in detail. Chen et al. [29] conducted creep tests on sandstone for different numbers of freeze-thaw cycles and analyzed the relationships between the creep deformation, creep rate, and long-term strength of the rock. Yang et al. [30] performed creep tests on quartzite under different freeze-thaw conditions (and different chemical solutions) and examined the effects of different chemical and freezethaw environments on the creep properties and microstructure of rocks. Li et al. [31] carried out creep tests on sandstone after exposure to freeze-thaw conditions and investigated the effect of freeze-thaw cycles on the creep deformation and pore structure of sandstone.

The creep characteristics of rocks under freeze-thaw conditions have been investigated to varying degrees. However, in terms of the effects of freeze-thaw cycles and confining pressure on rock creep behavior, detailed investigations have not been conducted, and few experimental data have been reported. Based on this research gap, multilevel loading and unloading triaxial creep tests under different numbers of freeze-thaw cycles and confining pressure conditions were carried out in this study using saturated red sandstone as the research object. The coupled effects of freeze-thaw cycles and confining pressure on the creep properties, long-term strength, and creep failure mode of red sandstone were determined, and the effect of freeze-thaw cycles on rock microstructure was analyzed using SEM. This study provides theoretical guidance for the long-term stability evaluation of rocks in cold regions.

\section{Materials and Methods}

2.1. Specimen Preparation. The red sandstone specimens in this study were collected from the Dafosi Coal Mine, which is located in the mid-west zone of the Binchang Mining Area, Jurassic Coalfield, Huanglong, Shaanxi Province, China. The location of the Dafosi Coal Mine is shown in the map in Figure 1. The shaft of the Dafosi Coal Mine was constructed using the freezing method. The rock formations consisted of mostly thick, weak medium- to fine-grained sandstones. The sampled rock layer was light brownish-red fine- to mediumgrained feldspar quartz sandstone, mainly composed of quartz, plagioclase, potash feldspar, and calcite. Drilling and coring operations were performed to retrieve the red sandstone block from the site. All the rock samples used in this study were obtained from the same red sandstone block to reduce the influence of variation in the rock samples on the test results. Additionally, the drilling direction was consistent with the rock deposition direction. Following the methods recommended by the International Society for Rock Mechanics [32], the core removed from the drill hole was cut and polished into a standard rock sample with a diameter of $50 \mathrm{~mm}$, a height of $100 \mathrm{~mm}$, and an end surface unevenness that did not exceed $0.02 \mathrm{~mm}$, as shown in Figure 2.

First, the rock samples that were visually different were removed, and the remaining rock samples were placed in an oven and dried at $105^{\circ} \mathrm{C}$ for $24 \mathrm{~h}$. After drying, an ultrasonic tester was used to measure the wave velocity of each dried rock sample. Their mass was also measured to determine their dry density. By grouping samples with similar longitudinal wave velocity and dry density results, the rock samples were categorized into five groups, with eight samples in each group, for a total of 40 samples (there are 20 conventional tests and 20 creep tests each). All the rock samples were saturated through vacuum pumping, and a constant pumping pressure of $0.1 \mathrm{MPa}$ was maintained. After pumping for $4 \mathrm{~h}$, the rock samples were stored under atmospheric pressure for $6 \mathrm{~h}$. After saturation, the mass of each saturated rock sample was measured to obtain their saturated density, saturated water content, and porosity. The average values of 


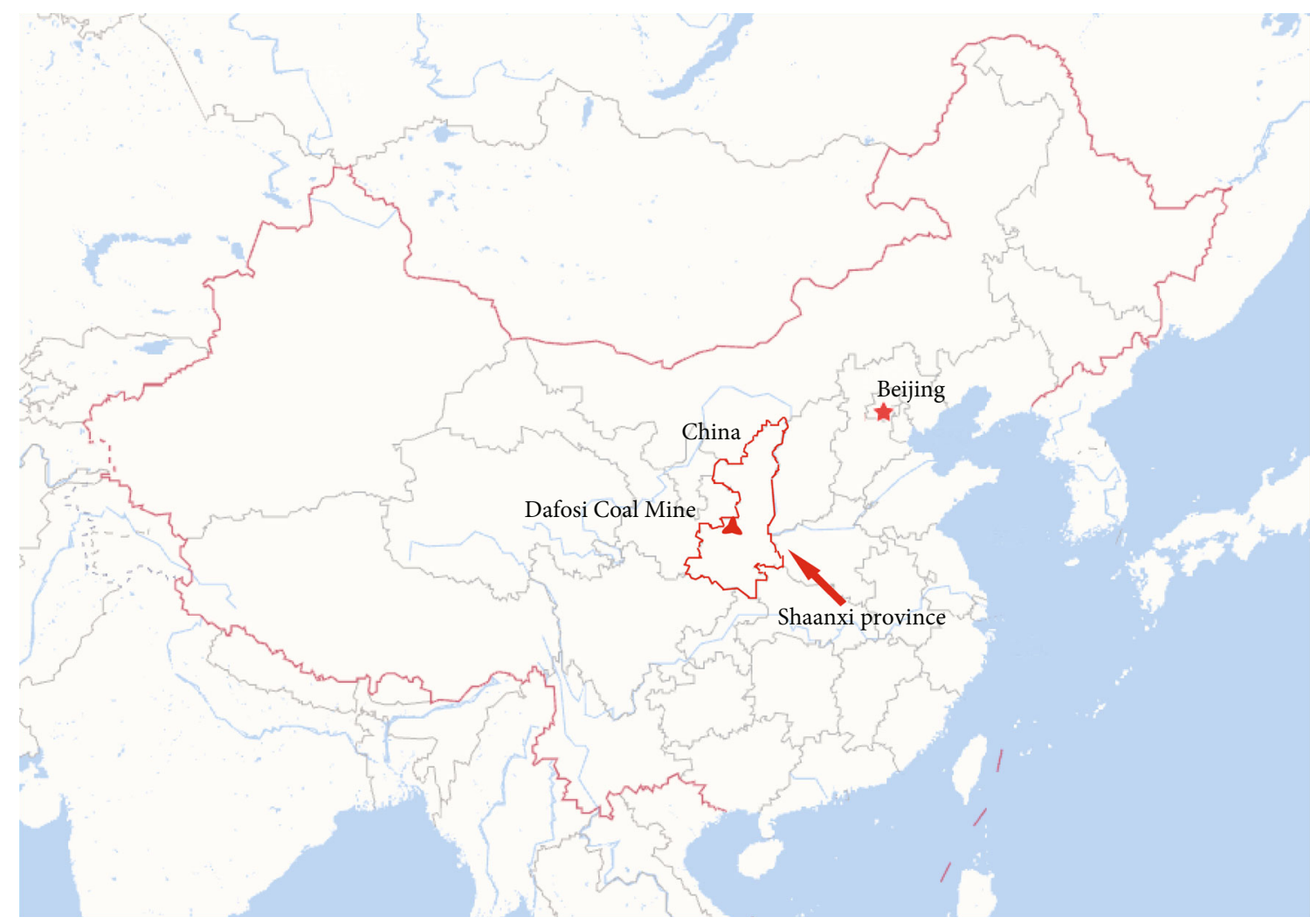

Figure 1: Location of the Dafosi Coal Mine, where the studied red sandstone was collected.

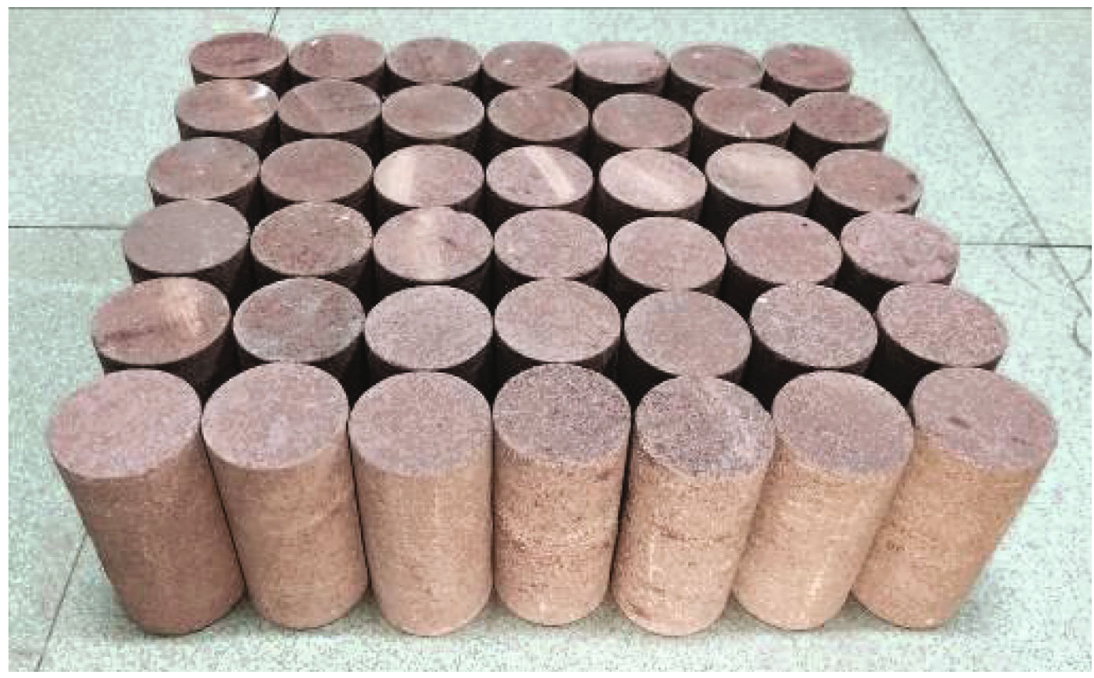

FIgURE 2: Red sandstone specimens.

TABLE 1: Physical properties of the studied red sandstone.

\begin{tabular}{lcccc}
\hline $\begin{array}{l}\text { P wave } \\
\text { velocity } \\
(\mathrm{m} / \mathrm{s})\end{array}$ & $\begin{array}{c}\text { Dry density } \\
\left(\mathrm{g} / \mathrm{cm}^{3}\right)\end{array}$ & $\begin{array}{c}\text { Saturated } \\
\text { density } \\
\left(\mathrm{g} / \mathrm{cm}^{3}\right)\end{array}$ & $\begin{array}{c}\text { Saturated water } \\
\text { content }(\%)\end{array}$ & $\begin{array}{c}\text { Porosity } \\
(\%)\end{array}$ \\
\hline 1211 & 2.24 & 2.35 & 5.31 & 9.6 \\
\hline
\end{tabular}

the physical properties of all the rock samples are listed in Table 1.

2.2. Testing Procedure. The prepared saturated red sandstone samples were placed in a freeze-thaw cycle test box for freeze-thaw cycle testing. The temperature and the duration of freezing and thawing were set based on the differences in temperature during the day and night in cold areas. In this study, the ambient temperatures during freezing and thawing were -20 and $20^{\circ} \mathrm{C}$, respectively. The 


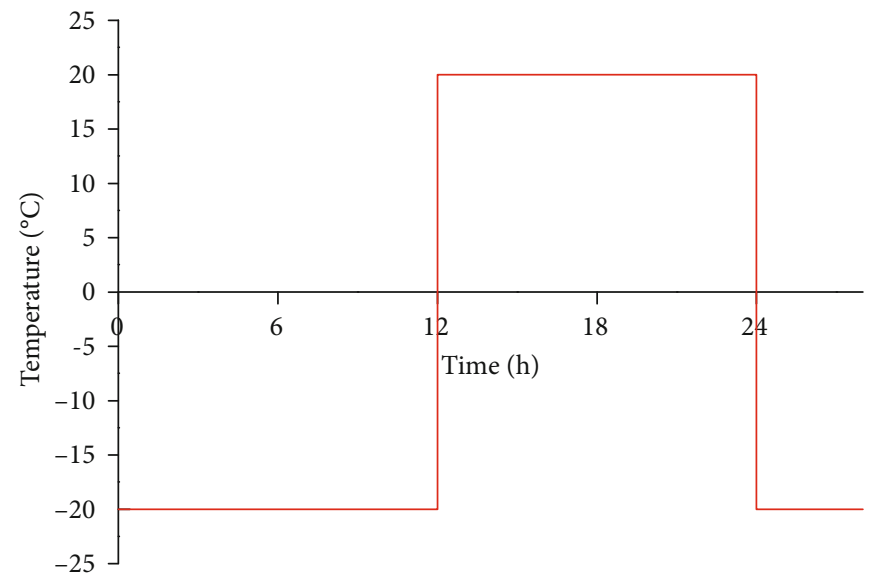

FiguRE 3: Temperature curve of a freeze-thaw cycle.

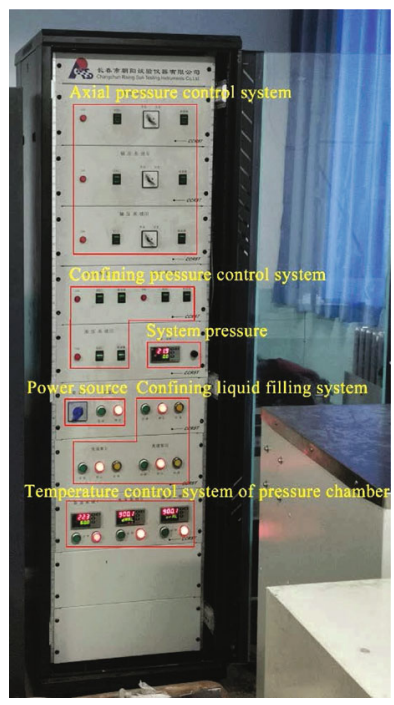

(a)

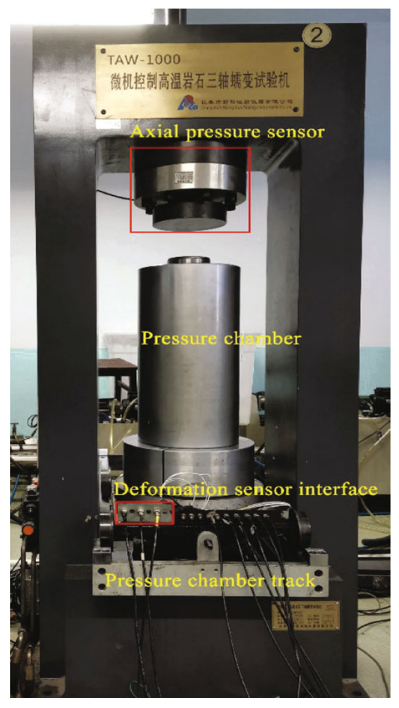

(b)

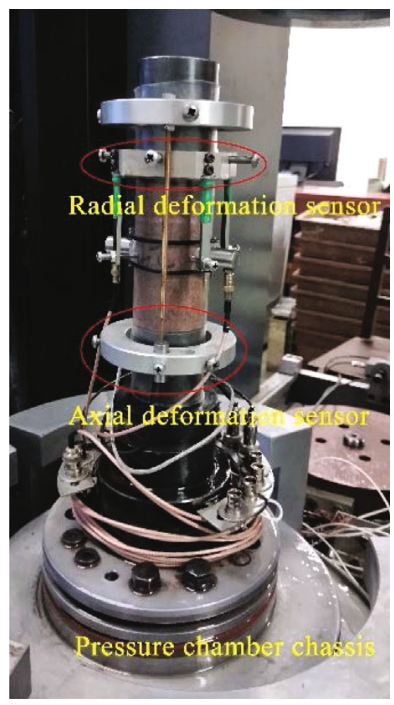

(c)

FIGURE 4: TAW-1000 rock triaxial creep testing machine: (a) electronic control system; (b) testing machine; (c) deformation measurement system.

freezing and thawing durations were $12 \mathrm{~h}$ each; thus, a freeze-thaw cycle lasted $24 \mathrm{~h}$. The temperature curve of a cycle is shown in Figure 3. Before implementing the freezing and thawing cycles, an initial test was performed on the rock samples. By observing the degree of particle shedding on the surface of the rock samples, it was determined that the different groups of rock samples would undergo $0,1,5$, 9, or 13 freeze-thaw cycles.

Conventional triaxial compression tests and multilevel loading and unloading triaxial creep tests were carried out using a TAW-1000 rock triaxial creep testing machine (Figure 4). The temperature of the test chamber was maintained at a constant value of $25^{\circ} \mathrm{C}$. The testing machine consisted of four main units: conventional triaxial, servo loading, deformation monitoring, and data acquisition units. The maximum axial load that could be applied using the testing machine was $1000 \mathrm{kN}$, and the maximum confining pressure was $100 \mathrm{MPa}$.
Conventional triaxial compression tests were performed at confining pressures of $0,2,4$, and $6 \mathrm{MPa}$ on the red sandstone samples after they were subjected to a varying number of freeze-thaw cycles. The triaxial compressive strength of each rock sample was determined, as listed in Table 2 The loading applied in the conventional triaxial compression tests was controlled by the stress, and the rate at which the load was applied was $0.01 \mathrm{MPa} / \mathrm{s}$.

Multilevel loading and unloading triaxial creep tests were performed on each group of rock samples at confining pressures of $0,2,4$, and $6 \mathrm{MPa}$. Based on the triaxial compressive strengths listed in Table 2, the magnitude of deviatoric stress of each rock sample was determined at various stress levels. The loading stress of the first level was $40 \%$ of the triaxial compressive strength, and the subsequent loading stress was increased by $10 \%$ of the triaxial compressive strength until rock sample failure occurred. Table 3 shows the deviatoric stress magnitudes of the rock samples for different 
TABLE 2: Results of the conventional triaxial compression tests of red sandstone after freezing-thawing.

\begin{tabular}{|c|c|c|c|c|c|c|}
\hline Freeze-thaw cycles & $\begin{array}{l}\text { Specimen } \\
\text { number }\end{array}$ & $\begin{array}{c}\text { Confining pressure } \\
(\mathrm{MPa})\end{array}$ & $\begin{array}{c}\text { Dry density } \\
\left(\mathrm{g} / \mathrm{cm}^{3}\right)\end{array}$ & $\begin{array}{l}\text { P wave velocity } \\
(\mathrm{m} / \mathrm{s})\end{array}$ & $\begin{array}{c}\text { Uniaxial compressive } \\
\text { strength }(\mathrm{MPa})\end{array}$ & $\begin{array}{c}\text { Elastic modulus } \\
(\mathrm{GPa})\end{array}$ \\
\hline \multirow{4}{*}{0} & $24-13$ & 0 & 2.23 & 1169 & 7.25 & 1.09 \\
\hline & $24-49$ & 2 & 2.23 & 1174 & 20.67 & 2.41 \\
\hline & $24-38$ & 4 & 2.23 & 1191 & 27.53 & 3.24 \\
\hline & $24-5$ & 6 & 2.23 & 1197 & 31.61 & 4.27 \\
\hline \multirow{4}{*}{1} & $24-51$ & 0 & 2.23 & 1137 & 6.07 & 0.80 \\
\hline & $24-47$ & 2 & 2.23 & 1238 & 19.13 & 2.27 \\
\hline & $24-15$ & 4 & 2.24 & 1220 & 25.82 & 3.15 \\
\hline & $24-18$ & 6 & 2.23 & 1280 & 29.97 & 3.66 \\
\hline \multirow{4}{*}{5} & $25-8$ & 0 & 2.23 & 1280 & 5.03 & 0.71 \\
\hline & $24-14$ & 2 & 2.24 & 1291 & 17.79 & 1.90 \\
\hline & $25-1$ & 4 & 2.24 & 1274 & 24.23 & 2.06 \\
\hline & $25-7$ & 6 & 2.24 & 1281 & 28.35 & 2.31 \\
\hline \multirow{4}{*}{9} & $25-13$ & 0 & 2.24 & 1258 & 4.52 & 0.61 \\
\hline & $25-9$ & 2 & 2.24 & 1273 & 16.86 & 1.65 \\
\hline & $25-14$ & 4 & 2.24 & 1271 & 23.19 & 1.76 \\
\hline & 25-11 & 6 & 2.24 & 1249 & 27.79 & 2.04 \\
\hline \multirow{4}{*}{13} & $25-12$ & 0 & 2.25 & 1289 & 4.32 & 0.60 \\
\hline & $25-3$ & 2 & 2.25 & 1293 & 16.51 & 1.44 \\
\hline & $25-2$ & 4 & 2.25 & 1317 & 22.68 & 1.65 \\
\hline & $25-10$ & 6 & 2.25 & 1302 & 27.47 & 1.85 \\
\hline
\end{tabular}

numbers of freeze-thaw cycles and confining pressures. During the loading period, the axial load was increased at a rate of $0.01 \mathrm{MPa} / \mathrm{s}$ to reach the targeted deviatoric stress level, and then a constant load was maintained. During the unloading period, the axial load was decreased at a rate of $0.03 \mathrm{MPa} / \mathrm{s}$ to reach a deviatoric stress of zero and then was removed. After a loading-unloading cycle was completed, the next stage was started following the same sequence. For each deviatoric stress level, the loading process lasted $48 \mathrm{~h}$, and the unloading process lasted $24 \mathrm{~h}$, except for the last level, in which there was no unloading. The specific loading method is shown in Figure 5.

2.3. Effect of Freeze-Thaw Cycles on the Microstructure of the Red Sandstone. X-ray diffraction was conducted to analyze the composition of red sandstone after 0 and 13 freezethaw cycles, as shown in Table 4 . The rock was mainly composed of quartz, plagioclase, potash feldspar, and calcite. After 13 freeze-thaw cycles, the proportions of plagioclase, calcite, and analcite in the rock decreased. This decrease occurred because the minerals that could easily react with water (such as plagioclase, calcite, and cristobalite) gradually dissolved under the action of the freeze-thaw cycles, resulting in a decrease in their mineral contents.

The red sandstone samples were observed using SEM after they were subjected to varying numbers of freeze-thaw cycles. An image archiving and communication system was used to process the SEM images to obtain binary images and rock parameters, such as the average length and area of the pores. Figure 6 shows SEM and binary images of red sandstone after different numbers of freeze-thaw cycles. The black part of a binary image (shown on the right side of the figure) represents the pores and microcracks encountered in the slice during scanning. The skeletal structure of the rock particles not subjected to freezing-thawing was relatively tight, the surface was relatively flat, and no noticeable pores were observed. Larger rock particles appeared on the surface of the slice, and relatively scattered pores existed between the particles in the slice. As the number of freezethaw cycles increased, the mineral components of the rock dissolved, forming large pores. With increasing number of freeze-thaw cycles, the grain boundaries gradually became more noticeable, and the cohesion between the rock particles decreased significantly.

\section{Experimental Results}

3.1. Results of the Conventional Triaxial Compression Tests. Owing to the influence of the variation in the rock samples on the creep tests, creep data at a confining pressure of $2 \mathrm{MPa}$ after 9 freeze-thaw cycles were analyzed. The results of the conventional triaxial compression test at a confining pressure of $2 \mathrm{MPa}$ after 9 freeze-thaw cycles were analyzed (Figure 7) to establish the relationship between the conventional mechanical properties and long-term mechanical properties of red sandstone. Table 2 and Figure 7 show that the number of freeze-thaw cycles and confining pressure 
TABLE 3: Deviatoric stress levels the during triaxial creep tests of red sandstone after freeze-thaw.

\begin{tabular}{|c|c|c|c|c|c|c|c|c|c|}
\hline \multirow{2}{*}{ Freeze-thaw cycles } & \multirow{2}{*}{ Confining pressure $(\mathrm{MPa})$} & \multirow{2}{*}{ Specimen number } & \multirow{2}{*}{$\mathrm{P}$ wave velocity $(\mathrm{m} / \mathrm{s})$} & \multicolumn{6}{|c|}{ Deviatoric stress level (MPa) } \\
\hline & & & & 1 st & 2nd & 3rd & 4th & 5 th & 6 th \\
\hline \multirow{4}{*}{0} & 0 & $24-8$ & 1148 & 2.90 & 3.63 & 4.35 & 5.08 & 5.80 & 6.53 \\
\hline & 2 & $24-6$ & 1185 & 8.27 & 10.34 & 12.40 & 14.47 & 16.54 & 18.60 \\
\hline & 4 & $24-12$ & 1153 & 11.81 & 14.77 & 17.72 & 20.67 & 23.62 & 26.58 \\
\hline & 6 & $24-45$ & 1197 & 12.64 & 15.81 & 18.97 & 22.13 & 25.29 & 28.45 \\
\hline \multirow{4}{*}{1} & 0 & $24-4$ & 1174 & 2.43 & 3.04 & 3.64 & 4.25 & 4.86 & 5.46 \\
\hline & 2 & $24-16$ & 1174 & 7.65 & 9.57 & 11.48 & 13.39 & 15.30 & 17.22 \\
\hline & 4 & $24-46$ & 1173 & 10.33 & 12.91 & 15.49 & 18.07 & 20.66 & 23.24 \\
\hline & 6 & $24-48$ & 1164 & 11.99 & 14.99 & 17.98 & 20.98 & 23.98 & 26.97 \\
\hline \multirow{4}{*}{5} & 0 & $24-17$ & 1180 & 2.01 & 2.12 & 3.02 & 3.52 & 4.02 & 4.53 \\
\hline & 2 & $24-9$ & 1191 & 7.12 & 8.90 & 10.67 & 12.45 & 14.23 & 16.01 \\
\hline & 4 & $24-27$ & 1174 & 9.70 & 11.47 & 13.25 & 15.03 & 16.81 & 18.59 \\
\hline & 6 & $24-43$ & 1191 & 11.34 & 14.18 & 17.01 & 19.85 & 22.68 & 25.52 \\
\hline \multirow{4}{*}{9} & 0 & $24-26$ & 1148 & 1.81 & 2.26 & 2.71 & 3.16 & 3.62 & 4.07 \\
\hline & 2 & $24-22$ & 1164 & 6.74 & 8.43 & 10.12 & 11.80 & 13.49 & 15.17 \\
\hline & 4 & $24-11$ & 1169 & 9.28 & 11.60 & 13.91 & 16.23 & 18.55 & 20.87 \\
\hline & 6 & $24-31$ & 1180 & 11.12 & 13.90 & 16.67 & 19.45 & 22.23 & 25.01 \\
\hline \multirow{4}{*}{13} & 0 & $24-2$ & 1174 & 1.73 & 2.16 & 2.59 & 3.02 & 3.46 & 3.89 \\
\hline & 2 & $24-1$ & 1180 & 6.60 & 8.26 & 9.91 & 11.56 & 13.21 & 14.86 \\
\hline & 4 & $24-31$ & 1180 & 9.07 & 11.34 & 13.61 & 15.88 & 18.14 & 20.41 \\
\hline & 6 & 24-19 & 1197 & 10.99 & 13.74 & 16.48 & 19.23 & 21.98 & 24.72 \\
\hline
\end{tabular}

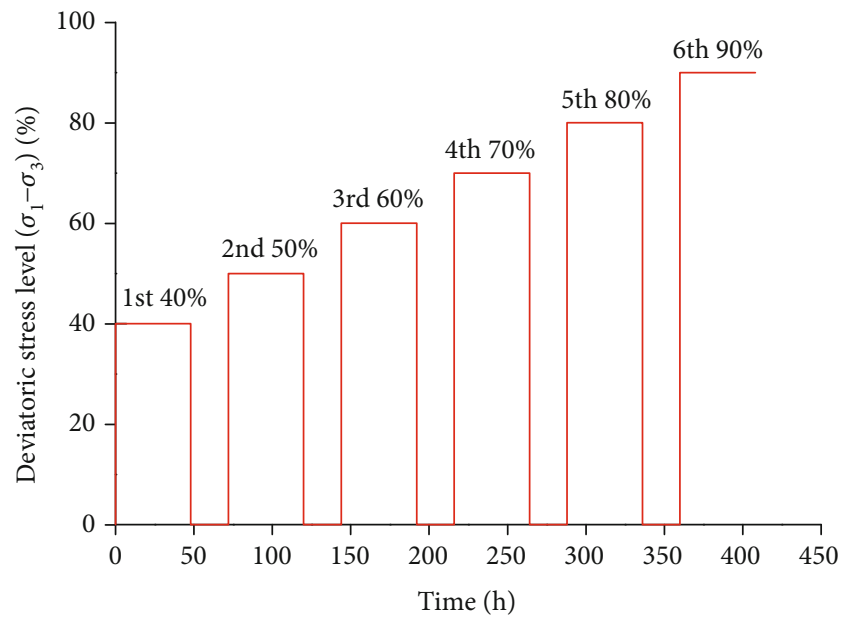

Figure 5: Multilevel loading and unloading process for triaxial creep testing.

had a significant effect on the triaxial compressive strength and elastic modulus of the rock.

At a confining pressure of $2 \mathrm{MPa}$, the triaxial compressive strength of the rock sample that was not subjected to any freeze-thaw cycle was 20.67 MPa. After 1 freeze-thaw cycle, the triaxial compressive strength was $19.13 \mathrm{MPa}$, which corresponded to a reduction of $7.45 \%$ compared to the strength of the sample subjected to zero freeze-thaw cycles. After 5 freeze-thaw cycles, the triaxial compressive strength was
17.79 $\mathrm{MPa}$, which was $7.00 \%$ less than that after 1 freezethaw cycle. As the number of freeze-thaw cycles increased, after 9 and 13 cycles, the triaxial compressive strength values decreased by $5.23 \%$ and $1.86 \%$ compared to the strength of the sample subjected to 5 freeze-thaw cycles, to 16.86 and 16.51 $\mathrm{MPa}$, respectively. The triaxial compressive strength of the rock gradually decreased with an increase in the number of freeze-thaw cycles, and the rate of decrease decreased continuously. The relationship between the triaxial compressive strength of the tested red sandstone and the number of freeze-thaw cycles under different confining pressure conditions was fitted (Figure 8). The coefficients of determination $\left(R^{2}\right)$ of the fitted curves were all higher than 0.95 . The fitting results are expressed in Equation (1). The triaxial compressive strength of the rock decreased exponentially with an increase in the number of freeze-thaw cycles under different confining pressures.

$$
\begin{cases}\sigma_{\mathrm{c}}=2.7187 e^{-N / 2.6522}+4.4165, & \sigma_{3}=0 \mathrm{MPa} \\ \sigma_{\mathrm{c}}=3.9479 e^{-N / 3.7732}+16.4890, & \sigma_{3}=2 \mathrm{MPa} \\ \sigma_{\mathrm{c}}=4.6444 e^{-N / 4.1010}+22.6163, & \sigma_{3}=4 \mathrm{MPa} \\ \sigma_{\mathrm{c}}=3.8594 e^{-N / 2.4240}+27.6346, & \sigma_{3}=6 \mathrm{MPa}\end{cases}
$$

where $\sigma_{c}, \sigma_{3}$, and $N$ represent the triaxial compressive strength, confining pressure, and number of freeze-thaw cycles, respectively. 
TABLE 4: X-ray diffraction analysis results of red sandstone.

\begin{tabular}{lccccccc}
\hline \multirow{2}{*}{ Freeze-thaw cycles } & & \multicolumn{2}{c}{ Red sandstone mineral content $\left(10^{-2}\right)$} & & \\
& Quartz & Plagioclase & Potash feldspar & Calcite & Illite & Chlorite & Analcite \\
\hline 0 & 53.0 & 17.9 & 9.9 & 9.9 & 2.9 & 2.9 & 3.5 \\
13 & 58.3 & 11.2 & 13.9 & 8.9 & 3.0 & 2.8 & 1.9 \\
\hline
\end{tabular}

Table 2 shows that the elastic modulus of the rock gradually increases with the confining pressure under the same freeze-thaw cycle conditions, while it gradually decreases with the number of freeze-thaw cycles under the same confining pressure. The relationship between the elastic modulus $E$ and the number of freeze-thaw cycles $N$ under different confining pressure conditions was fitted (Figure 9 ). The coefficients of determination $\left(R^{2}\right)$ of the fitted curves exceeded 0.95 except at a confining pressure of $0 \mathrm{MPa}$. The fitting results are expressed in Equation (2). The elastic modulus decreased exponentially with an increase in the number of freeze-thaw cycles under different confining pressures, which was similar to the variation trend of the triaxial compressive strength.

$$
\begin{cases}E=0.4833 e^{-N / 0.9730}+0.6392, & \sigma_{3}=0 \mathrm{MPa} \\ E=1.4742 e^{-N / 12.4990}+0.9219, & \sigma_{3}=2 \mathrm{MPa} \\ E=1.8512 e^{-N / 4.7618}+1.4908, & \sigma_{3}=4 \mathrm{MPa} \\ E=2.4479 e^{-N / 3.2485}+1.8305, & \sigma_{3}=6 \mathrm{MPa}\end{cases}
$$

where $E, \sigma_{3}$, and $N$ represent the triaxial compressive strength, confining pressure, and number of freeze-thaw cycles, respectively.

3.2. Results of the Multilevel Loading and Unloading Triaxial Creep Tests. Figure 10 shows the multilevel loading and unloading creep curves for the tested red sandstone under different freeze-thaw and confining pressure conditions. The red sandstone creep curves corresponding to $2 \mathrm{MPa}$ of confining pressure and $0,1,5$, and 9 freeze-thaw cycles all exhibited three stages: the reduced creep rate (initial creep), constant creep rate (steady-state creep), and increased creep rate (accelerated creep) states. After 13 freeze-thaw cycles, the rock damage caused by freezing-thawing was relatively significant, considering the variation in the rock samples. One rock sample was destroyed during loading of the fifth stress level $\left(80 \% \sigma_{c}\right)$ and failed to reach the accelerated creep stage. Except for the rock samples under 1 and 13 freeze-thaw cycles, the other rock samples reached the accelerated creep stage at the sixth stress level $\left(90 \% \sigma_{c}\right)$, which was consistent with the test results obtained by $[33,34]$. At the same confining pressure, the instantaneous deformation and creep deformation of the tested red sandstone increased with the applied stress until the rock sample failed. The freeze-thaw cycle had a significant effect on the rock deformation. The deformation of the rock samples gradually increased with the number of freeze-thaw cycles, and the effect of the freeze-thaw cycles on the rock deformation became more significant with the increase in the stress level.
Under the same number of freeze-thaw cycles, the creep deformation of the rock samples gradually increased with the confining pressure, which was different from previous research results in which the creep deformation of rocks decreased with the increase in confining pressure at a similar stress level $[35,36]$. This difference arose because different magnitudes of loading stress were adopted in this study and previous studies to reach the same stress level. In previous studies, a certain deviatoric stress was taken as the loading stress under different confining pressures to reach the same stress level. However, in this study, the loading stress was a percentage of the triaxial compressive strength under this condition. Therefore, for the same stress level, when the confining pressure was different, the value of the loading stress was also different. For example, after 9 freeze-thaw cycles, the loading stress of the third level was $60 \% \sigma_{c}$ which was equal to $10.12 \mathrm{MPa}$ at a confining pressure of $2 \mathrm{MPa}$ but 13.91 $\mathrm{MPa}$ at a confining pressure of $4 \mathrm{MPa}$. Hence, the test results were different from those of previous studies. The red sandstones experienced the three abovementioned stages of creep under different confining pressure conditions. At the same loading stress level, the instantaneous deformation and creep deformation of the rock samples increased with the confining pressure. The confining pressure had a significant effect on both the instantaneous and creep deformations of the red sandstone. With the increase in the stress level, the effect of the confining pressure on the deformation of the red sandstone became more significant.

3.3. Effect of Freeze-Thaw Cycles on the Creep Characteristics of the Red Sandstone. The relationship between the instantaneous strain and the number of freeze-thaw cycles at various stress levels under $2 \mathrm{MPa}$ of confining pressure is shown in Figure 11. At the same stress level, the instantaneous strain of the rock samples increased with the number of freezethaw cycles. At a stress level of $60 \% \sigma_{c}$, the instantaneous strain of the rock sample that underwent 0 freeze-thaw cycles was $0.4278 \times 10^{-2}$. After 1 freeze-thaw cycle, the instantaneous strain increased by $31.21 \%$, corresponding to a value of $0.5613 \times 10^{-2}$. As the number of freeze-thaw cycles increased, after 5, 9, and 13 freeze-thaw cycles, the instantaneous strains of the rock samples were $0.6909 \times 10^{-2}$, $0.7294 \times 10^{-2}$, and $0.7774 \times 10^{-2}$, respectively, signifying a corresponding increase of $23.09 \%, 5.57 \%$, and $6.57 \%$. The instantaneous strain increased with the number of freezethaw cycles, but the rate of increase gradually decreased with the increase in the number of cycles and tended to stabilize.

Based on the data processing method of the multilevel loading and unloading creep tests, the instantaneous strains of the rock at various stress levels comprised the instantaneous elastic strain and instantaneous plastic strain, considering the 


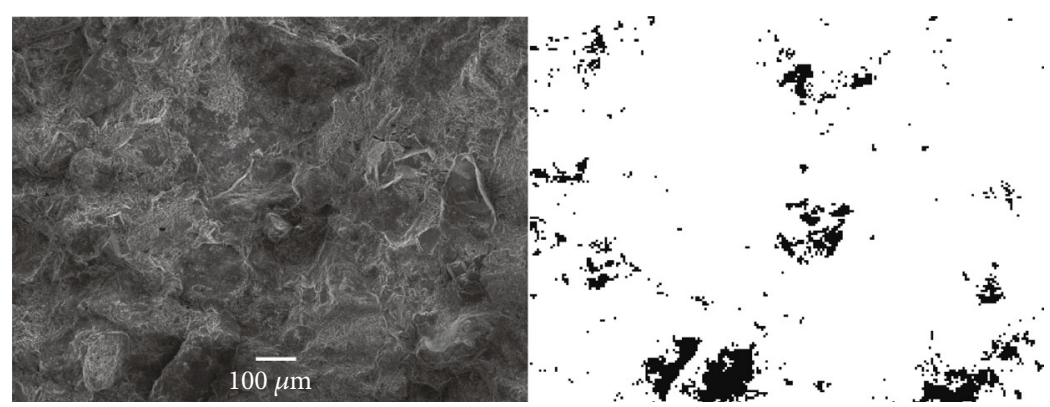

(a) 0 freeze-thaw cycle
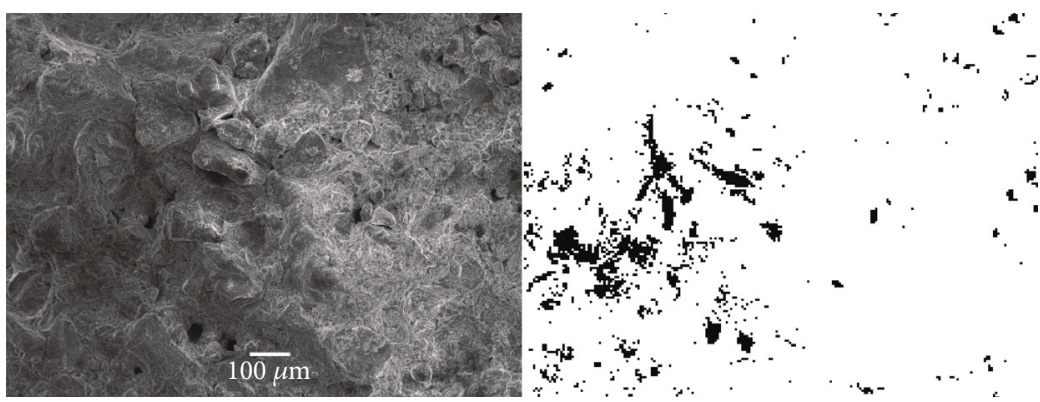

(b) 1 freeze-thaw cycle
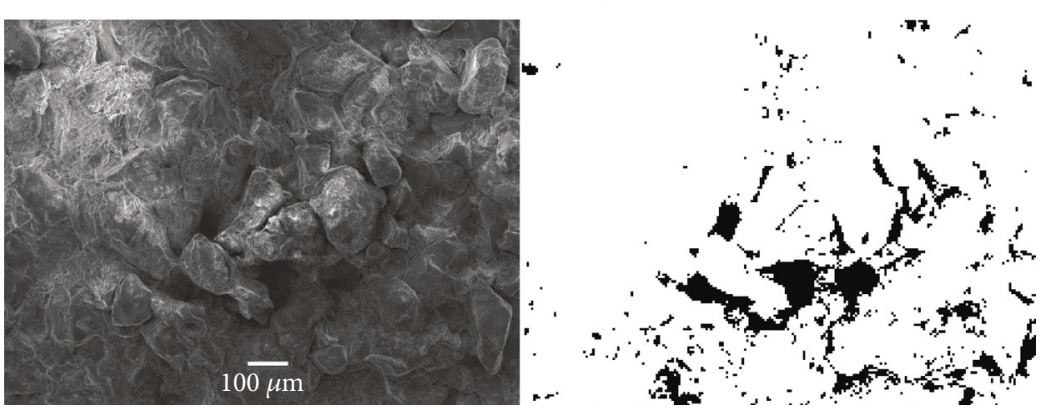

(c) 5 freeze-thaw cycles

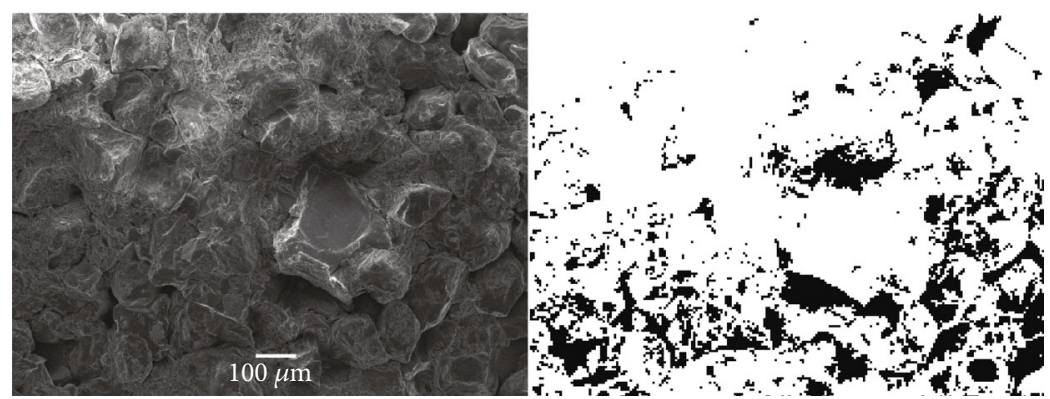

(d) 9 freeze-thaw cycles

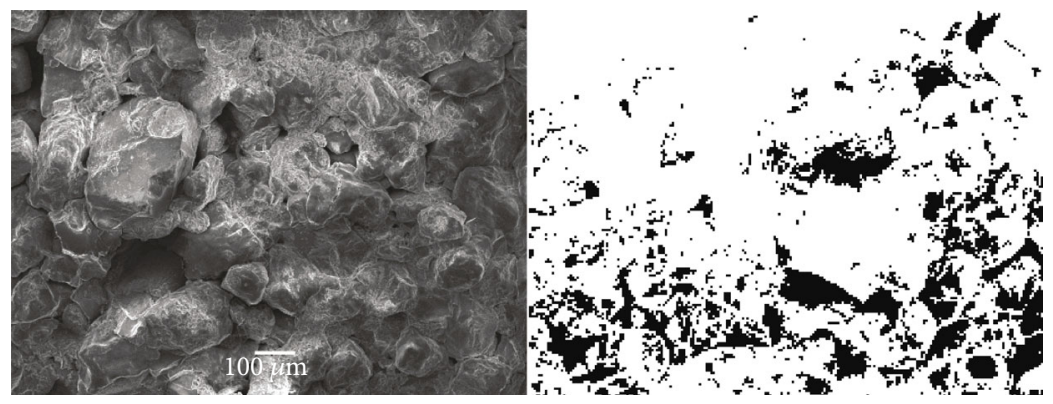

(e) 13 freeze-thaw cycles

FIGURE 6: SEM and binary images of red sandstone after (a) 0, (b) 1 (c) 5, (d) 9, and (e) 13 numbers of freeze-thaw cycles. 

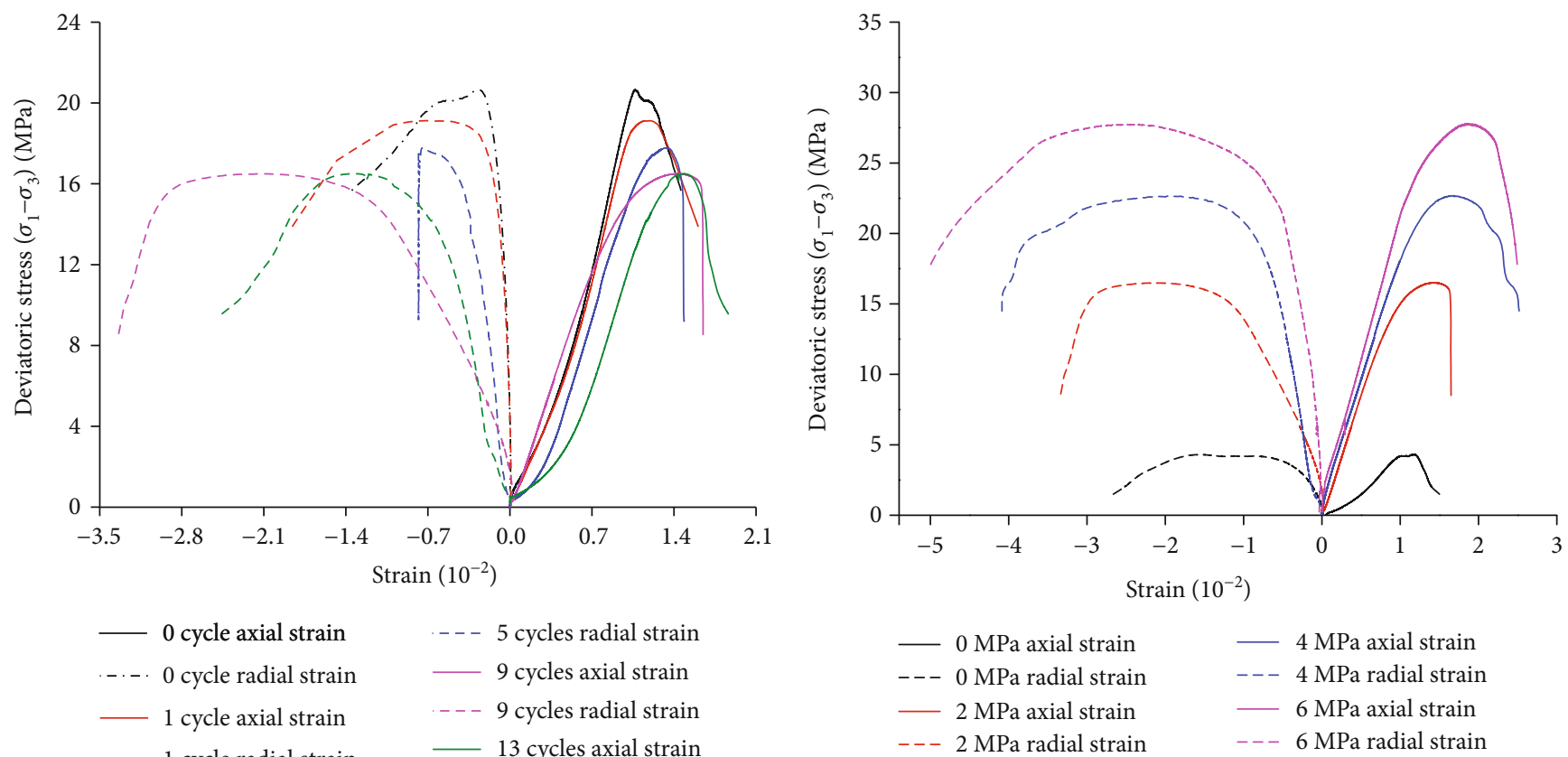

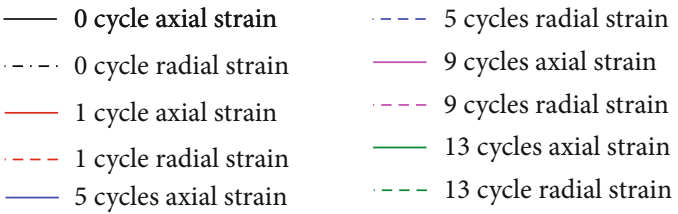

(a) Curves of strain of red sandstone versus deviatoric stress at $2 \mathrm{MPa}$ confining pressure (b) Curves of strain of red sandstone versus deviatoric stress under 9 freeze-thaw cycles

FiguRE 7: Curves of the tested red sandstone strain versus the applied deviatoric stress level for different (a) numbers of freeze-thaw cycles and (b) confining pressures.

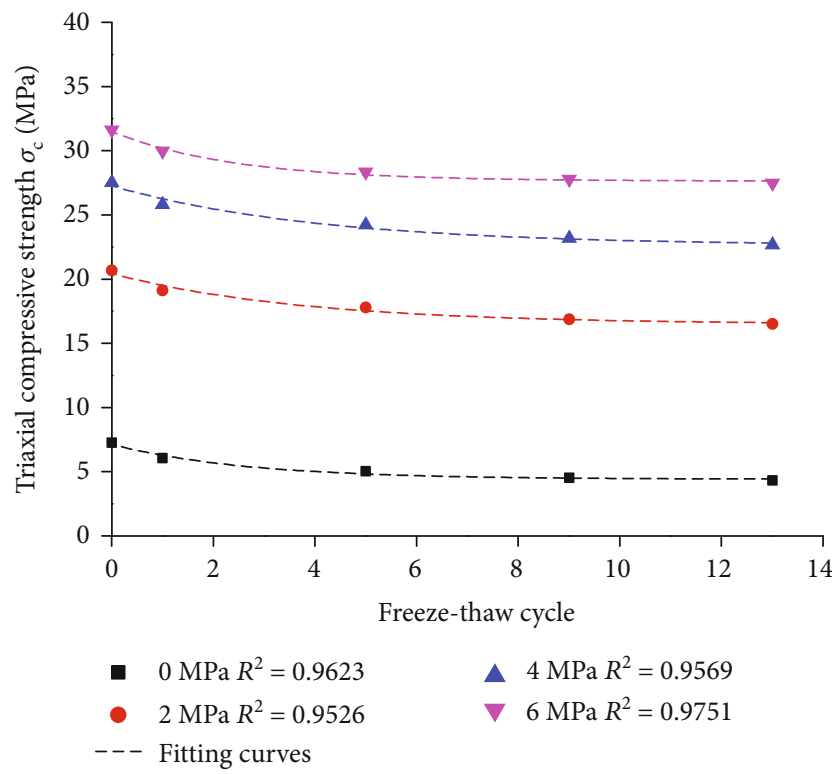

Figure 8: Curves of the triaxial compressive strength of the tested red sandstone versus the number of freeze-thaw cycles under different confining pressures.

loading history $[37,38]$. Figure 12 shows the instantaneous elastic and plastic strains versus the number of freeze-thaw cycles at various stress levels under $2 \mathrm{MPa}$ of confining pressure. The instantaneous elastic strain gradually increased with the number of freeze-thaw cycles at the same stress level, and its rate of increase was similar to that of the total instantaneous

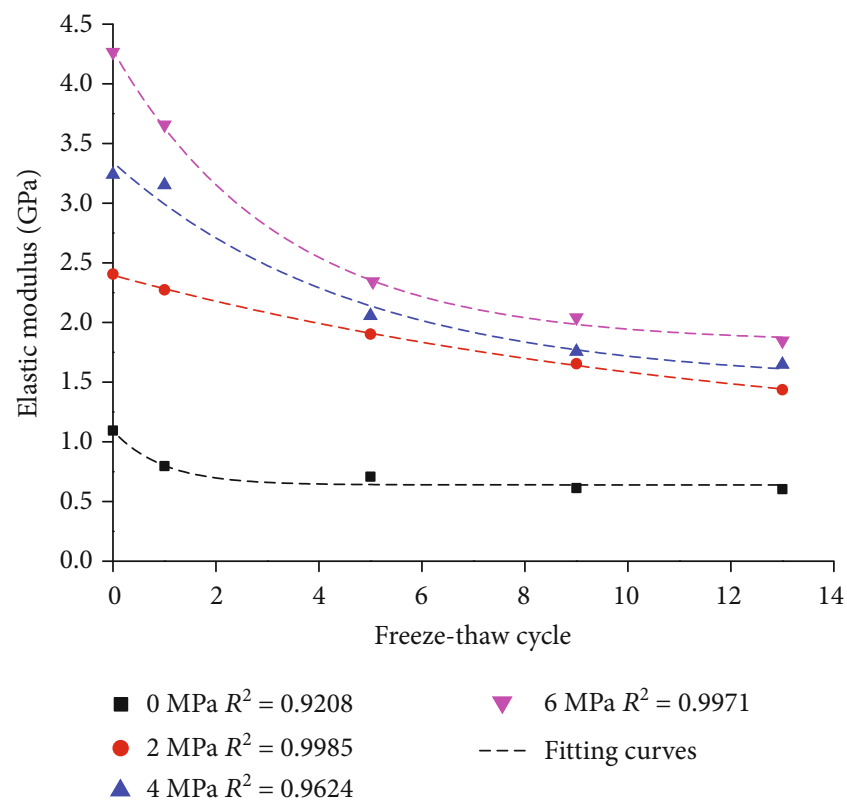

FIGURE 9: Curves of the elastic modulus of the tested red sandstone versus the number of freeze-thaw cycles under different confining pressures.

strain. The instantaneous plastic strain increased almost linearly with the number of freeze-thaw cycles, and the rates of increase were similar at various stress levels.

Figure 13 plots the creep strain against the number of freeze-thaw cycles for various stress levels before the rock 


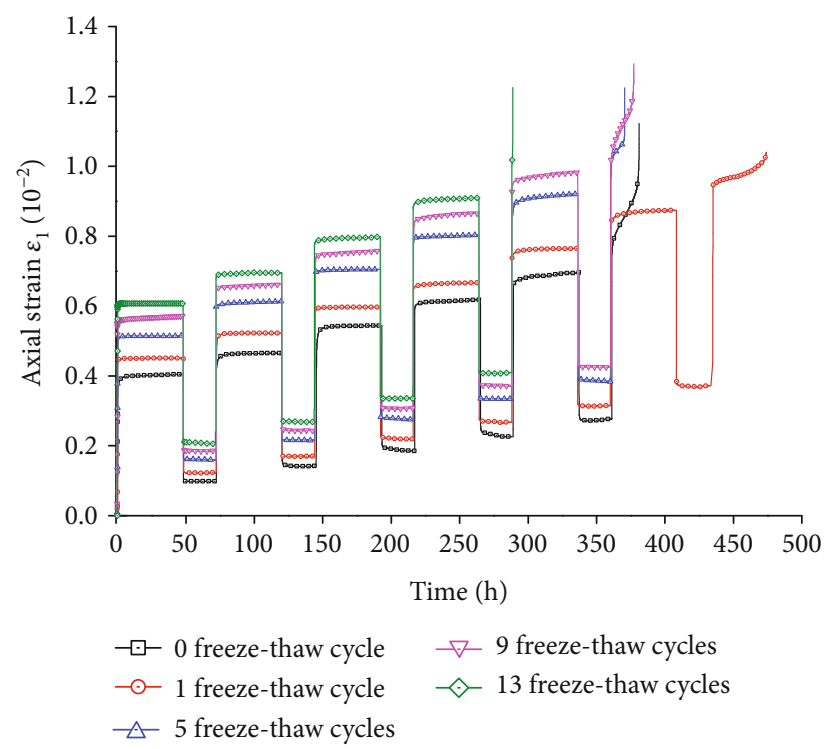

(a) Multilevel loading and unloading creep curves of red sandstone under $2 \mathrm{MPa}$ confining pressure

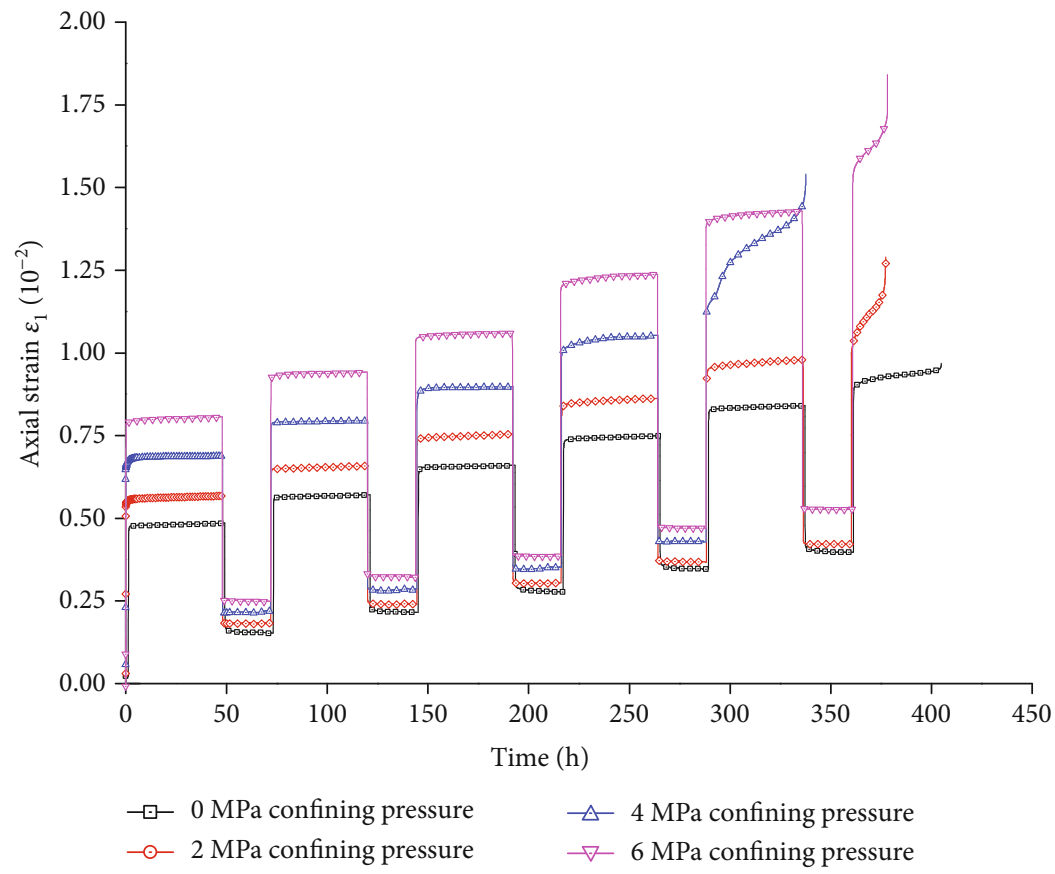

(b) Multilevel loading and unloading creep curves of red sandstone under 9 freeze-thaw cycles

FIGURE 10: Multilevel loading and unloading creep curves of the tested red sandstone after different (a) numbers of freeze-thaw cycles and (b) confining pressures.

samples entered the accelerated creep stage. The creep strain gradually increased with the number of freeze-thaw cycles at the same stress level. When the stress level was low (less than $60 \% \sigma_{\mathrm{c}}$ ), the creep strain increased almost linearly with the number of freeze-thaw cycles, and the rate of increase was low. When the stress level was high (above $60 \% \sigma_{c}$ ), the creep strain increased nonlinearly with the number of freeze-thaw cycles, and the rate of increase was high. For example, at the $50 \% \sigma_{\mathrm{c}}$ stress level, the creep strains after 1 and 9 freeze-thaw cycles were $0.2249 \times 10^{-3}$ and $0.2611 \times 10^{-3}$, respectively, indicating an increase of $16.10 \%$. At the $70 \%$ $\sigma_{\mathrm{c}}$ stress level, the creep strains after 1 and 9 freeze-thaw cycles were $0.4598 \times 10^{-3}$ and $0.6447 \times 10^{-3}$, respectively, representing an increase of $40.21 \%$. The freeze-thaw cycles had a significant effect on the creep deformation of the rock samples, and the freeze-thaw cycle effect was more significant when the stress level of the creep load was higher.

Depending on the data processing method used for analyzing the multilevel loading and unloading creep, the creep strain can be classified into the viscoelastic strain and the 


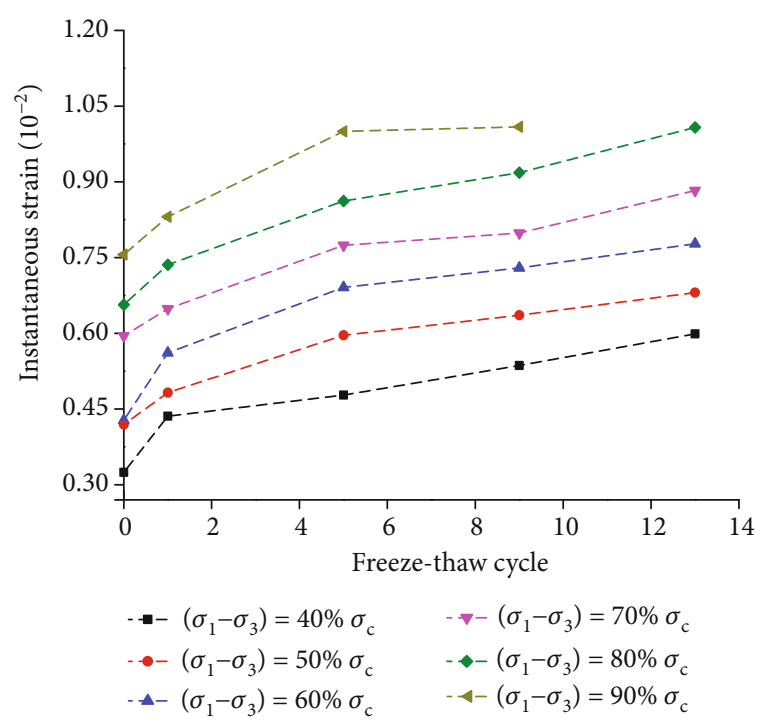

FIGURE 11: Curves of the instantaneous strain versus the number of freeze-thaw cycles at various stress levels under $2 \mathrm{MPa}$ of confining pressure.

viscoplastic strain. Figure 14 shows the relationship between the viscoelastic and viscoplastic strains at various stress levels and the number of freeze-thaw cycles under $2 \mathrm{MPa}$ of confining pressure. The viscoelastic strain of the red sandstone showed a gradual increase with the number of freeze-thaw cycles at the same stress level, and the variation in the viscoelastic strain with the increase in the number of freeze-thaw cycles was similar to that of the creep strain. The viscoplastic strain showed a relatively stable increase with the number of freeze-thaw cycles at various stress levels, and the viscoplastic strain did not significantly nonlinearly increase with the stress level.

Figure 15 shows the steady-state creep rate of the rock samples under the fourth loading stress level after being subjected to different numbers of freeze-thaw cycles at a confining pressure of $2 \mathrm{MPa}$. The steady-state creep rate increased nonlinearly with the number of freeze-thaw cycles under similar confining pressures and at the same stress level. The increase in the steady-state creep rate was significant when the number of freeze-thaw cycles was small. The steadystate creep rate was $9.8513 \times 10^{-5}$ for 0 freeze-thaw cycles but was $1.1203 \times 10^{-4}$ after 1 freeze-thaw cycle, representing an increase of $13.72 \%$. As the number of freeze-thaw cycles increased, the rate of increase in the steady-state creep rate gradually decreased. After 9 freeze-thaw cycles, the steadystate creep rate was $1.5147 \times 10^{-4}$, and after 13 freeze-thaw cycles, the value was $1.6175 \times 10^{-4}$, signifying an increase of $6.79 \%$. The freeze-thaw cycles had a considerable effect on the steady-state creep rate of this rock. The test results were fitted to quantitatively describe the relationship between the steady-state creep rate of the tested rock and the number of freeze-thaw cycles, as depicted in Figure 15. The fitting results are expressed in

$$
\dot{\varepsilon}_{\mathrm{c}}=1.8331 \times 10^{-6}-8.2663 \times 10^{-7} e^{-N / 9.6592},
$$

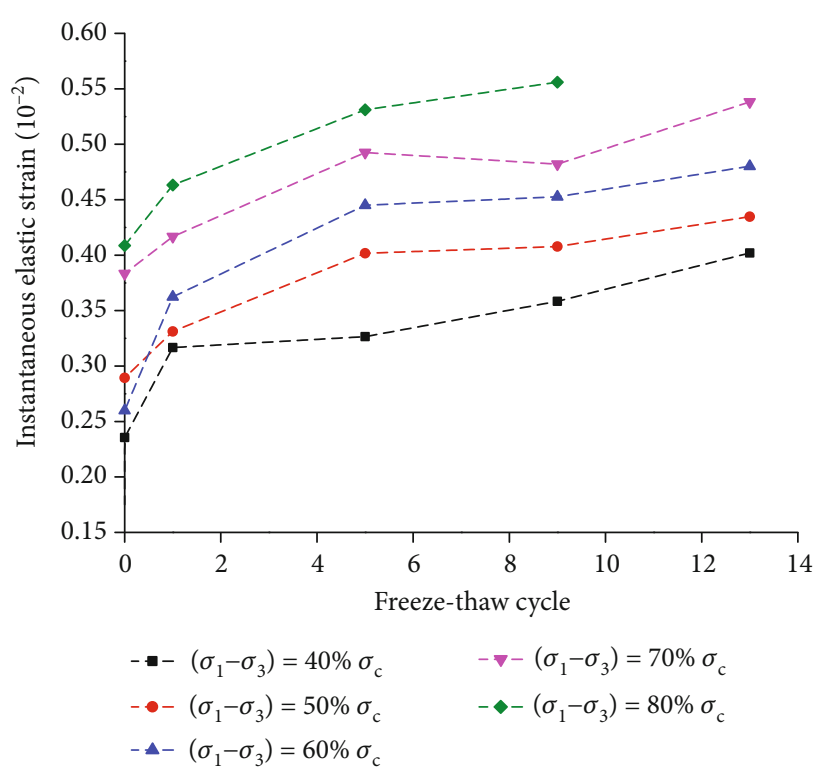

(a) Instantaneous elasticity strain

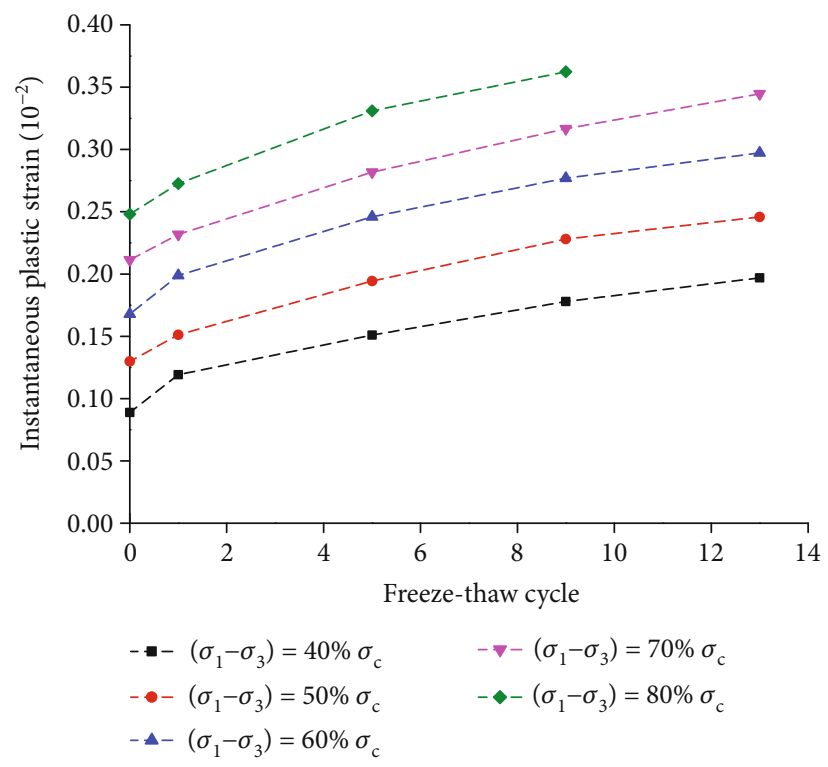

(b) Instantaneous plastic strain

FIgURE 12: Curves of (a) instantaneous elastic strain and (b) instantaneous plastic strain versus the number of freeze-thaw cycles at various stress levels under $2 \mathrm{MPa}$ of confining pressure.

where $\dot{\varepsilon}$ and $N$ represent the creep rate and the number of freeze-thaw cycles, respectively. The resulting coefficient of determination $\left(R^{2}\right)$ was 0.9865 .

As indicated by Figure 15, the exponential expression can be used to describe the relationship between the steady-state creep rate of the rocks and the number of freeze-thaw cycles.

3.4. Effect of Confining Pressure on the Creep Characteristics of the Red Sandstone. After 9 freeze-thaw cycles, the relationship between the instantaneous strain of the rock samples and the confining pressure was determined at various stress 


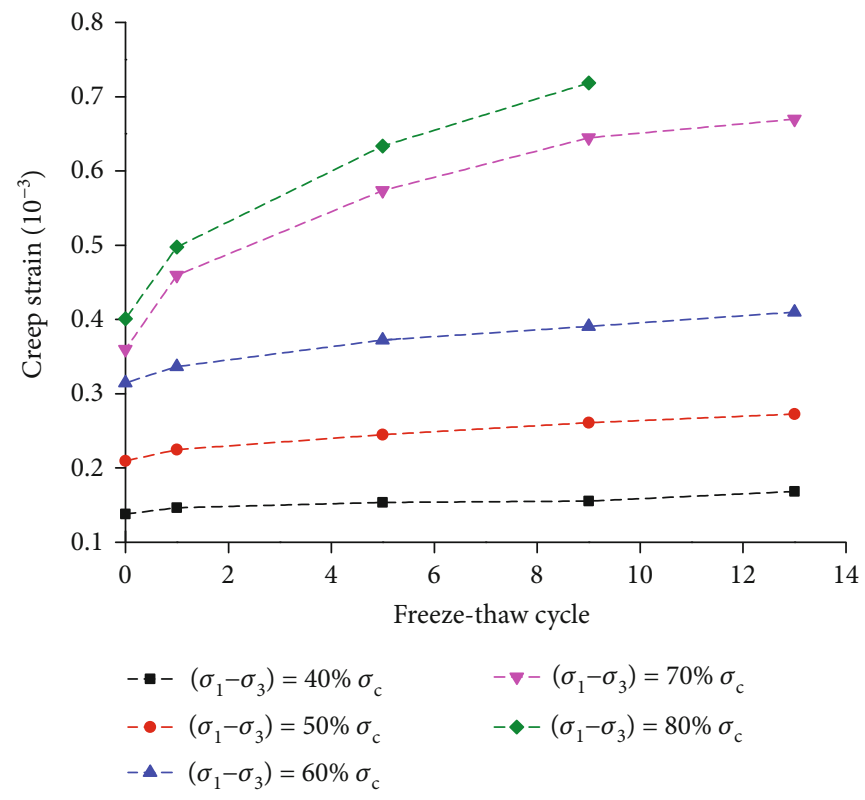

FIGURE 13: Curves of the creep strain versus the number of freeze-thaw cycles at various stress levels under $2 \mathrm{MPa}$ of confining pressure.

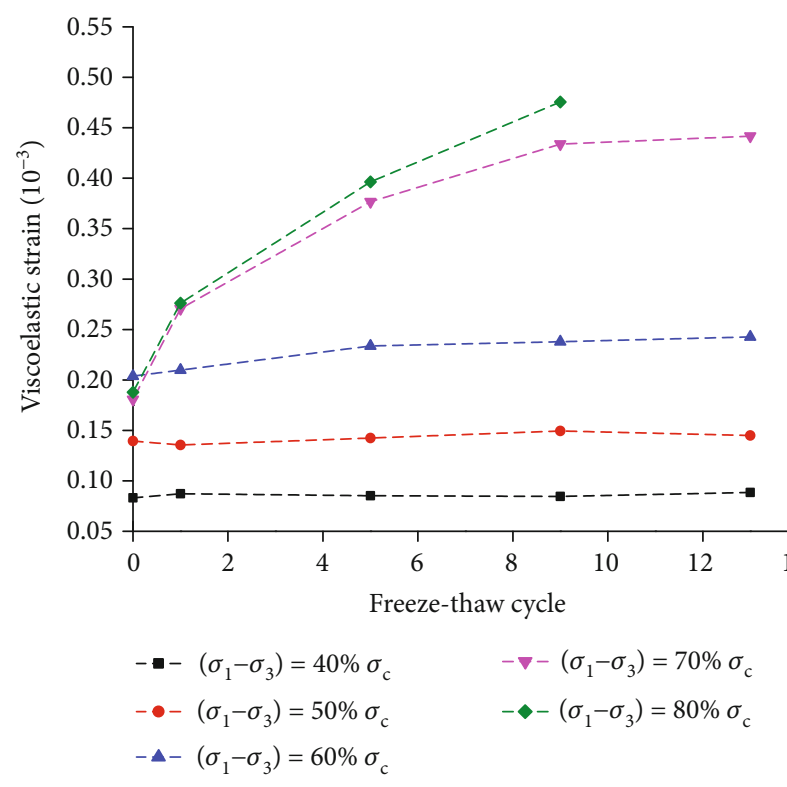

(a) Viscoelastic strain

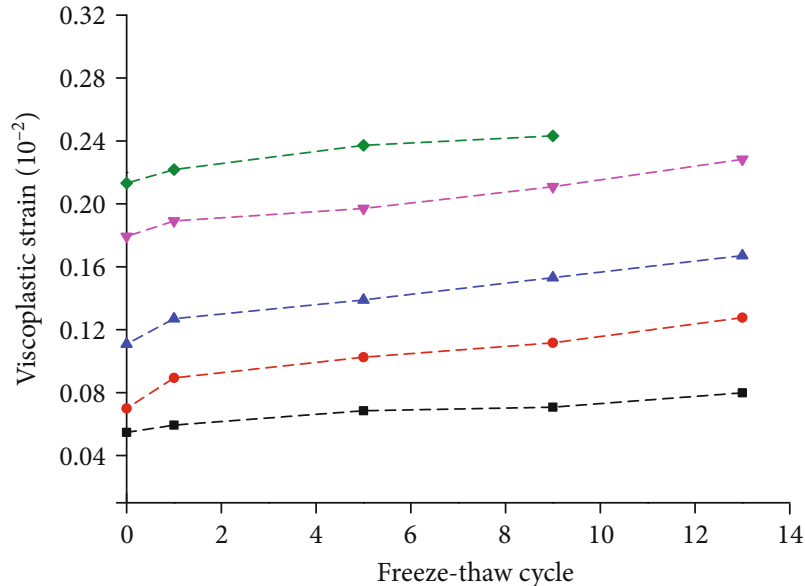

$$
\begin{array}{rlrl}
--\left(\sigma_{1}-\sigma_{3}\right) & =40 \% \sigma_{c} & & -\nabla-\left(\sigma_{1}-\sigma_{3}\right)=70 \% \sigma_{c} \\
-\bullet & \left(\sigma_{1}-\sigma_{3}\right)=50 \% \sigma_{c} & - & -\left(\sigma_{1}-\sigma_{3}\right)=80 \% \sigma_{c} \\
-\triangle-\left(\sigma_{1}-\sigma_{3}\right) & =60 \% \sigma_{c} &
\end{array}
$$

(b) Viscoplastic strain

Figure 14: Curves of (a) viscoelastic strain and (b) viscoplastic strain versus the number of freeze-thaw cycles at various stress levels under $2 \mathrm{MPa}$ of confining pressure.

levels (Figure 16). The instantaneous strain steadily increased with the confining pressure at the same stress level. The confining pressure had a significant effect on the instantaneous deformation of the rock samples, and this effect was more noticeable as the confining pressure increased. The instantaneous deformation of the tested red sandstone increased nearly linearly with the confining pressure at a low stress level. As the stress level increased, the instantaneous strain increased nonlinearly with the confining pressure. When the stress loading level was $80 \% \sigma_{c}$, the instantaneous strain increased almost parabolically with the confining pressure, and the nonlinearity was significant.

Figure 17 shows curves of the creep strain versus the confining pressure after 9 freeze-thaw cycles for various stress levels. When the stress level was low, the creep strain of the rock increased almost linearly with the confining pressure. The increase in the creep strain was nonlinear when the stress level was high, and the increase in the confining pressure caused the creep strain to increase rapidly. As the confining pressure increased, the rate of increase in the creep strain 


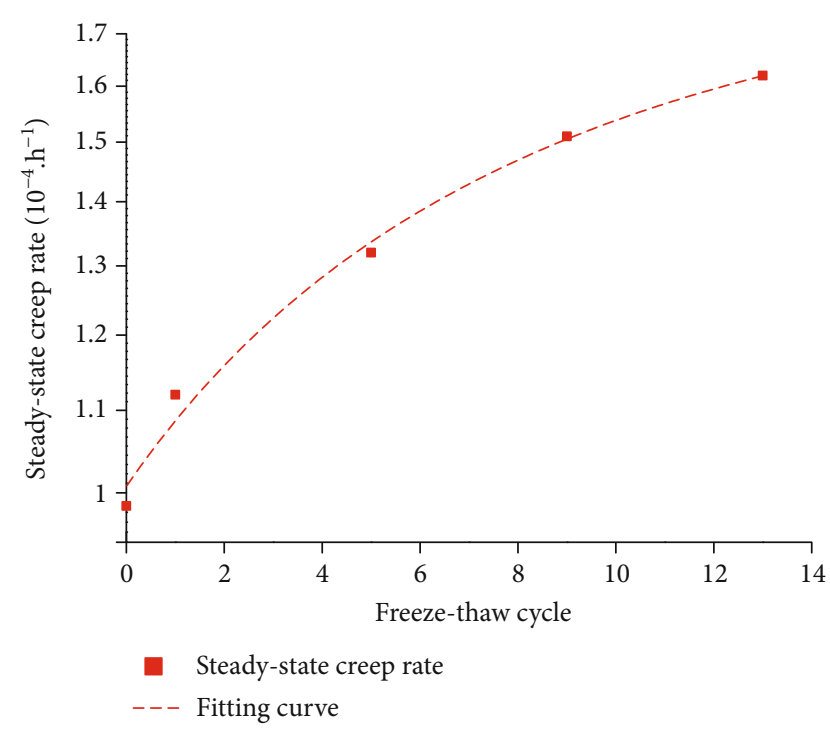

FIGURE 15: Curve of the steady-state creep rate versus the number of freeze-thaw cycles at the fourth loading stress level under $2 \mathrm{MPa}$ of confining pressure.

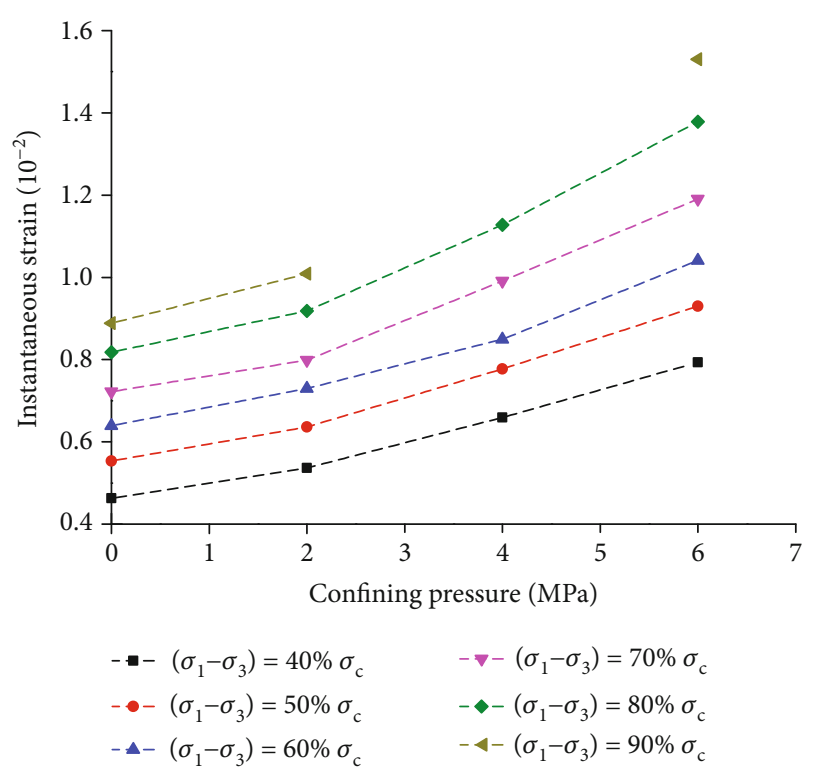

FIGURE 16: Curves of the instantaneous strain versus the confining pressure after 9 freeze-thaw cycles for various stress levels.

decreased and then became stable. When the confining pressure was low, a higher stress level caused the confining pressure to have a more significant effect on the creep strain. However, as the confining pressure continued to increase, the effect of the confining pressure on the creep strain eventually disappeared.

The relationship between the confining pressure and the steady-state creep rate of the rock samples under the fourth loading stress level after 9 freeze-thaw cycles was plotted in Figure 18. The confining pressure had a significant effect on the steady-state creep rate. The relationship between the con-

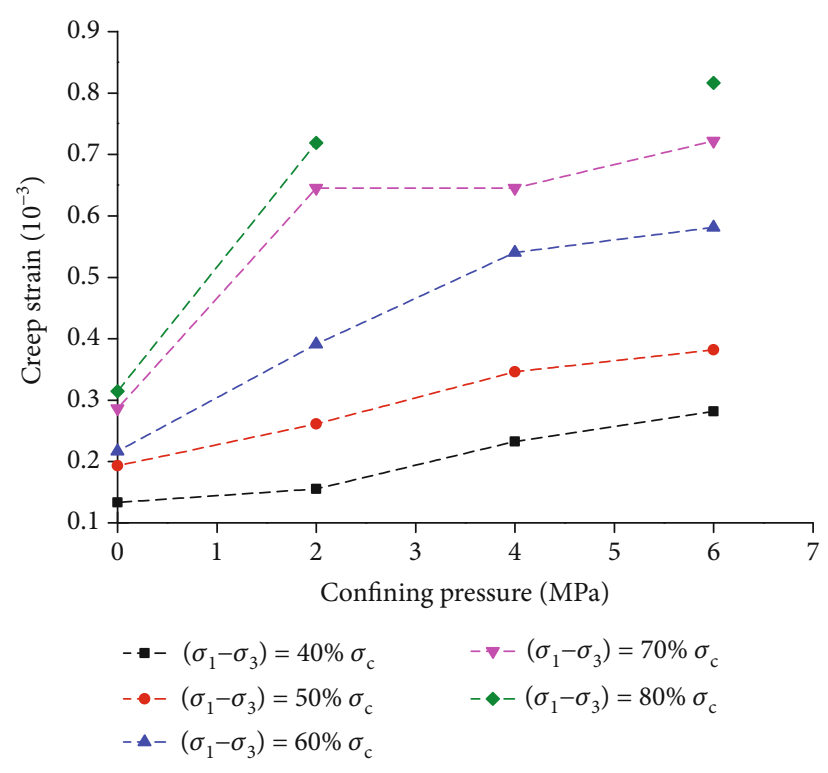

FIGURE 17: Curves of the creep strain versus the confining pressure after 9 freeze-thaw cycles for various stress levels.

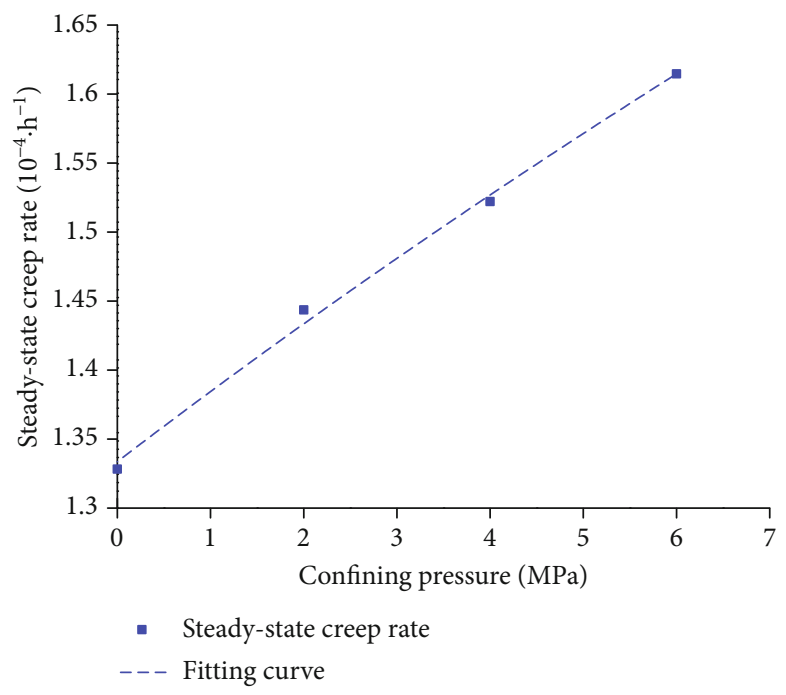

FIgURE 18: Curve of the steady-state creep rate versus the confining pressure at the fourth loading stress level after 9 freeze-thaw cycles.

fining pressure and steady-state creep rate of the red sandstone was fitted. The resulting coefficient of determination $\left(R^{2}\right)$ was 0.9967 , and the fitting relationship is expressed in

$$
\dot{\varepsilon}_{\mathrm{c}}=4.8828 \times 10^{-8} \sigma_{3}+1.3221 \times 10^{-6},
$$

where $\dot{\varepsilon}$ and $\sigma_{3}$ denote the creep rate and the confining pressure, respectively.

The steady-state creep rate increased linearly with the confining pressure, and its rate of increase was linear and unaffected by the confining pressure (Figure 18). The reason was that the increase in the confining pressure increased the triaxial compressive strength of the rock. At the same stress level, the higher the confining pressure, the higher the 


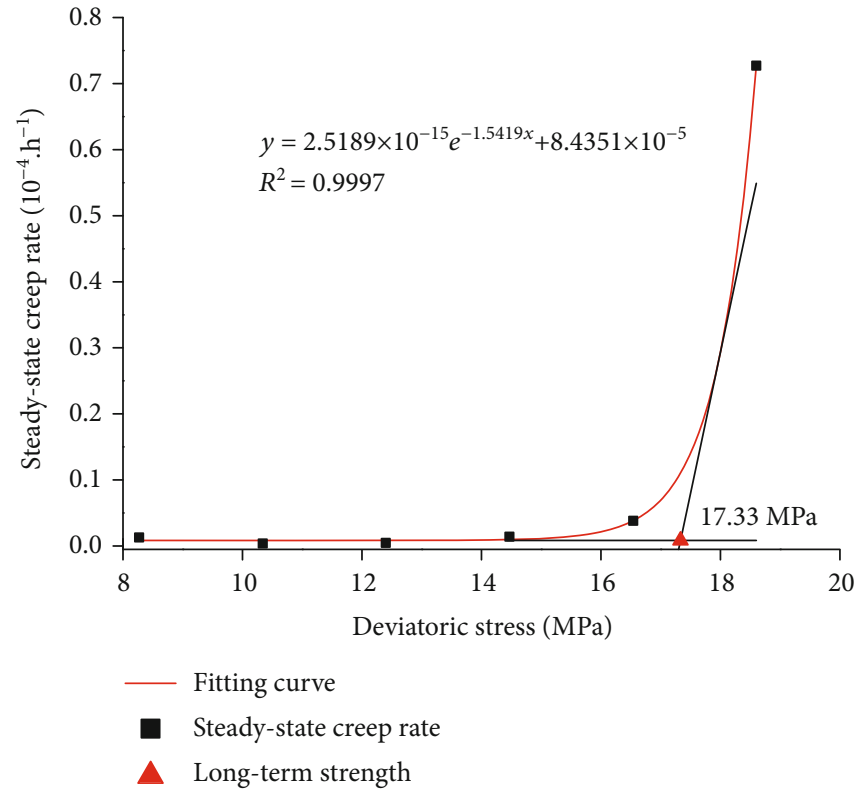

(a) 0 freeze-thaw cycle

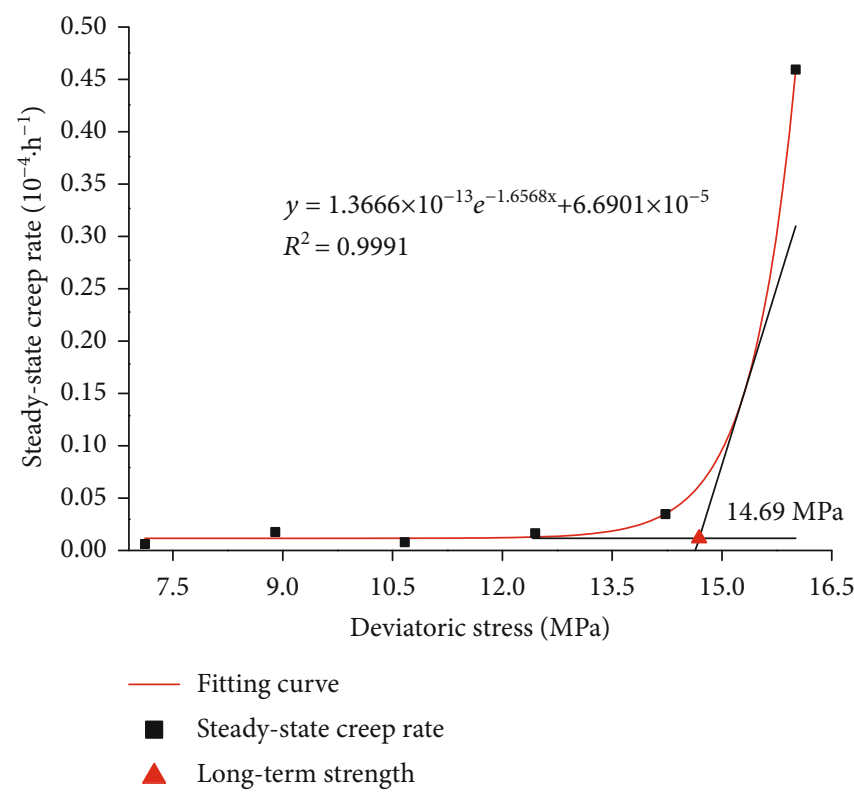

(c) 5 freeze-thaw cycles

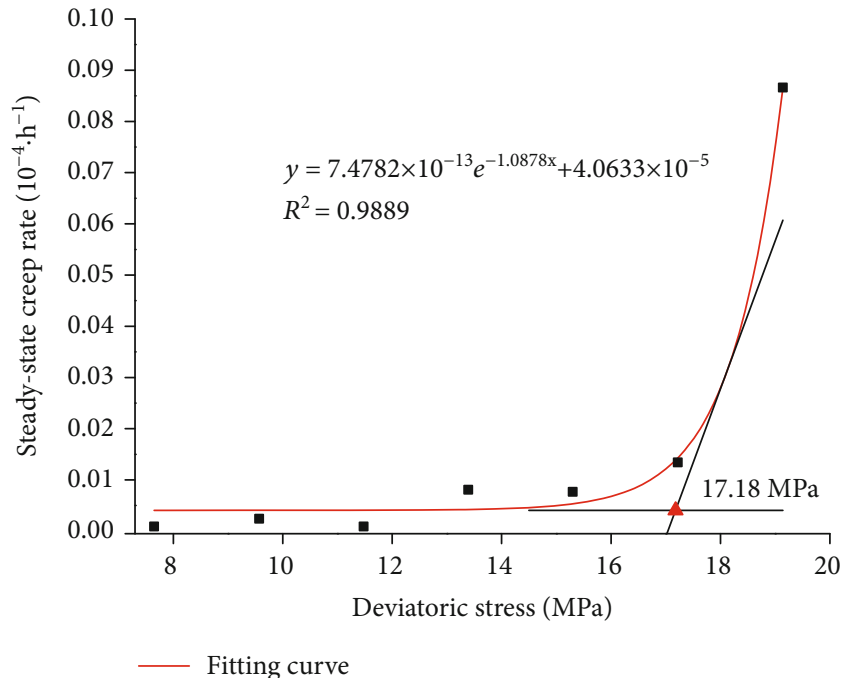

- Steady-state creep rate

A Long-term strength

(b) 1 freeze-thaw cycle

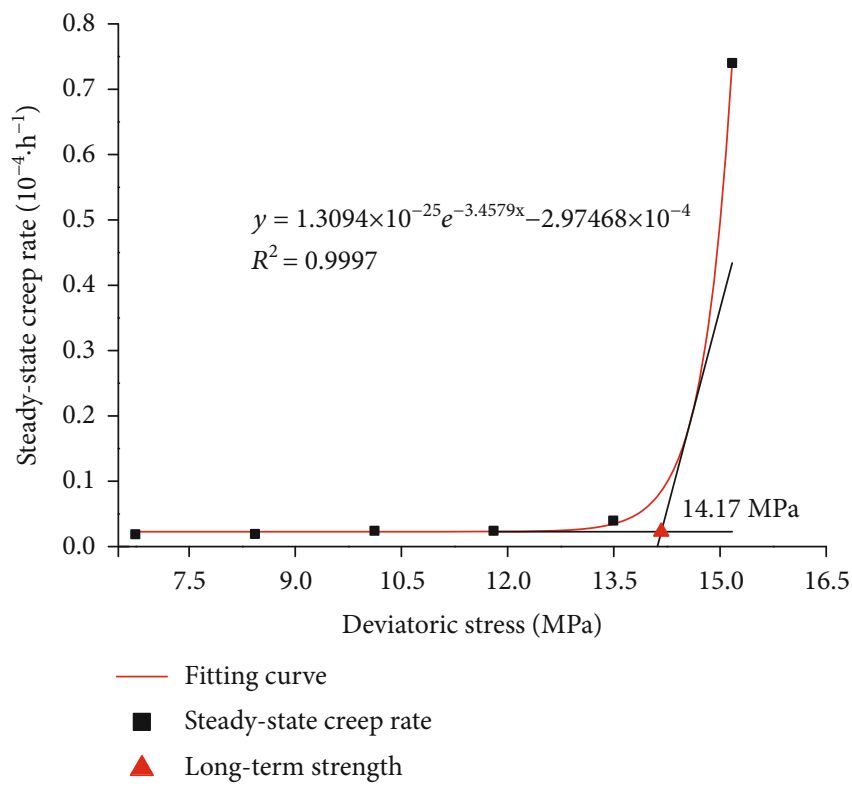

(d) 9 freeze-thaw cycles

Figure 19: Continued. 


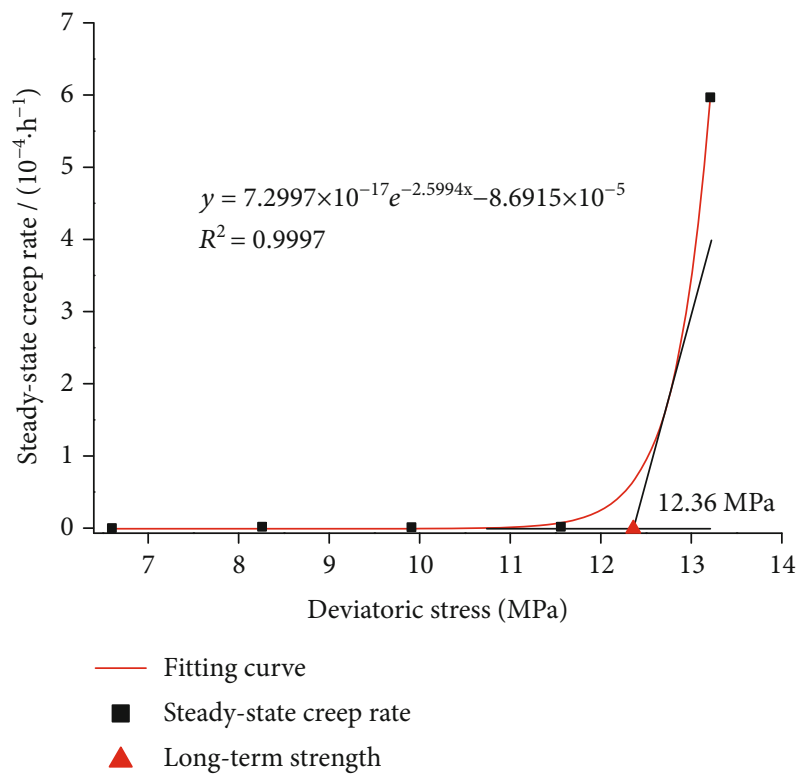

(e) 13 freeze-thaw cycles

FIGURE 19: Steady creep rate of the tested red sandstone under (a) 0, (b) 1, (c) 5, (d) 9, and (e) 13 numbers of freeze-thaw cycles.

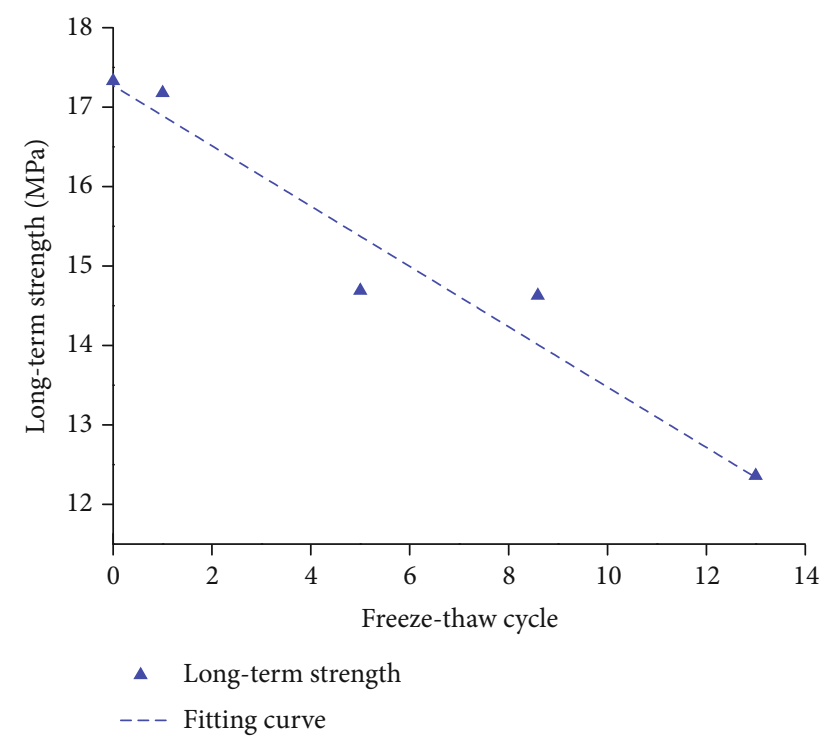

FIGURE 20: Curves of the long-term strength versus the number of freeze-thaw cycles under $2 \mathrm{MPa}$ of confining pressure.

deviatoric stress value; hence, the creep rate of the rock was also higher.

3.5. Long-Term Strength of the Red Sandstone after FreezingThawing. The long-term strength of rock is the critical stress at the transition from stable creep to unsteady creep. When the stress in the rock is lower than this critical stress value, the rock will creep stably, and no matter how long this stress state is maintained, the rock will not experience failure. However, when the stress exceeds the long-term strength, the rock will experience unstable creep until creep failure occurs [39-41].

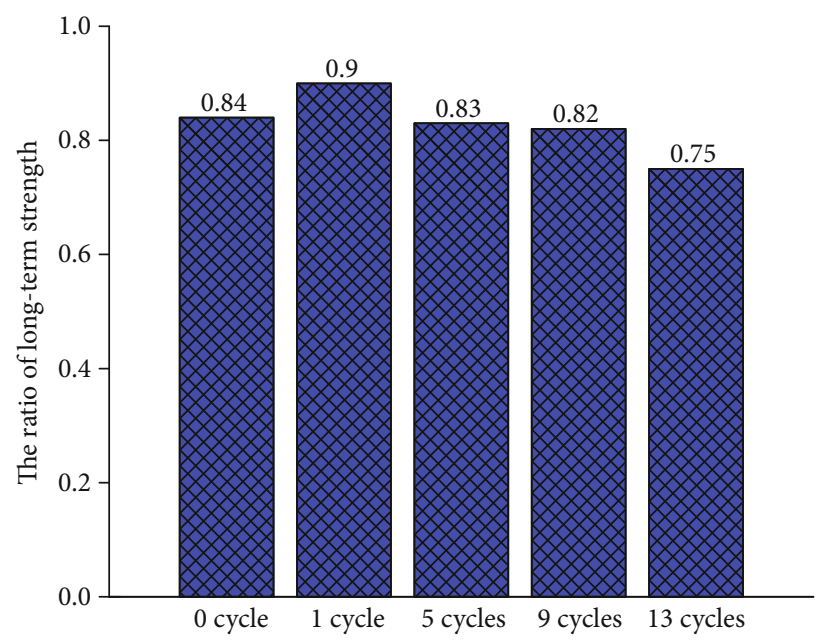

FIGURE 21: Long-term strength ratio of the tested red sandstone under $2 \mathrm{MPa}$ of confining pressure for different numbers of freezethaw cycles.

Currently, the isochronous stress-strain curve cluster, transition creep, and steady-state creep rate methods are the three most widely used methods of determining the long-term strength of rocks. The steady-state creep rate method and the transition creep method have a similar basic principle; the long-term strength of the rock is determined by the change in the creep rate. During creep, the steady-state creep rate of the rock increases with the loading stress level. When the stress level is lower than the long-term strength, the steady-state creep rate of the rock gradually decreases to zero with increasing time, yet the rock will not experience failure. When the stress level exceeds the long-term strength, the creep rate will increase after a period of steady-state 


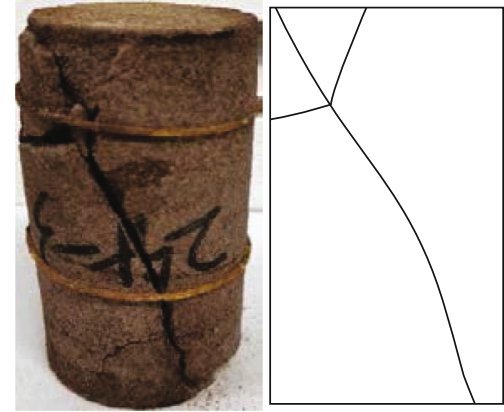

(a) $0 \mathrm{MPa}, 0$ freeze-thaw cycles

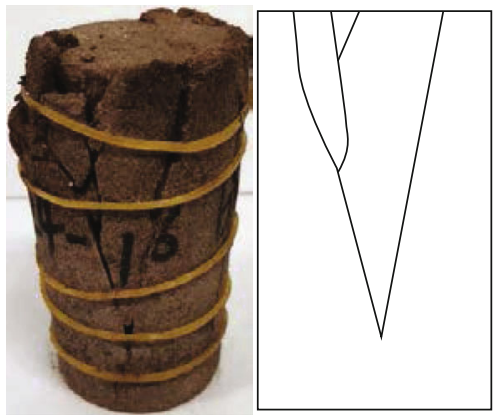

(c) $4 \mathrm{MPa}, 0$ freeze-thaw cycles

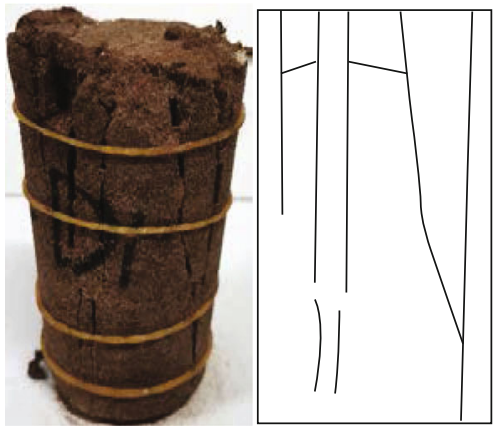

(e) $4 \mathrm{MPa}, 1$ freeze-thaw cycle

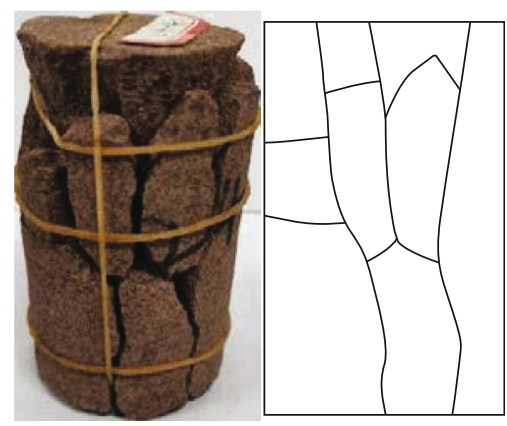

(g) $4 \mathrm{MPa}, 9$ freeze-thaw cycles

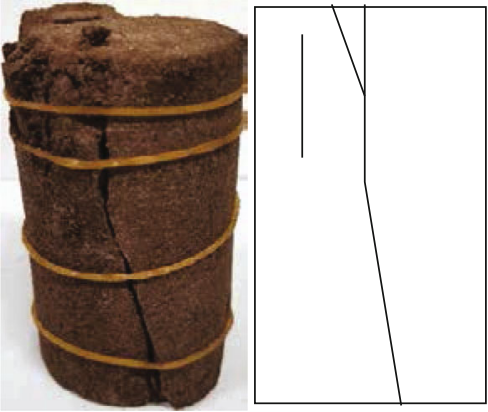

(b) $2 \mathrm{MPa}, 0$ freeze-thaw cycles

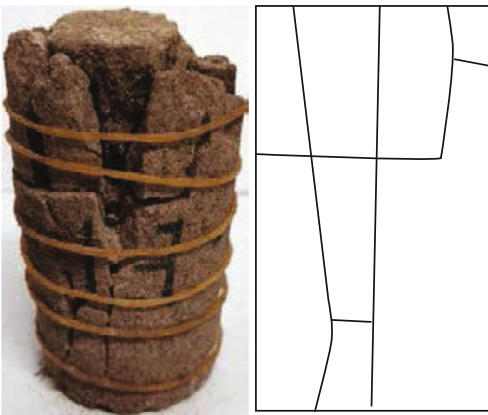

(d) $6 \mathrm{MPa}, 0$ freeze-thaw cycles

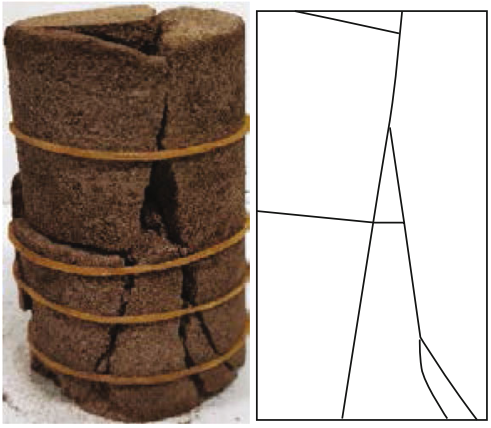

(f) $4 \mathrm{MPa}, 5$ freeze-thaw cycles

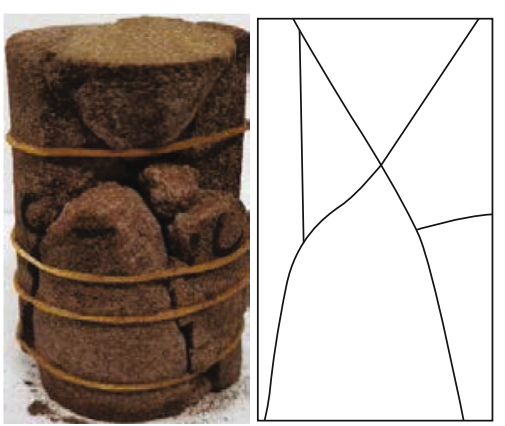

(h) $4 \mathrm{MPa}, 13$ freeze-thaw cycles

Figure 22: Creep failure modes of the tested red sandstone under different numbers of freeze-thaw cycles and confining pressures and corresponding sketches.

creep, and the rock will enter the accelerated creep stage before ultimately failing.

Based on the above description, an improved steady-state creep rate method was used in this study to determine the long-term strength of the rock [42]. The relationship between the steady-state creep rate and the partial stress at various stress levels was analyzed. The results showed that the steady-state creep rate increased with the deviatoric stress before reaching the critical inflection point, but the rate of increase was small. However, the rock entered the unsteady creep stage when the curve suddenly increased beyond the critical inflection point. The relationship between the steady-state creep rate and the deviatoric stress data was fitted to plot the relationship curve. Before the critical 
inflection point, the fitted curve is almost parallel to the horizontal axis, and the rock is in the steady-state creep stage. The black straight line in the figure is the tangent line where the steady-state creep growth rate is " 0 ," and the black diagonal line is the tangent line at the critical inflection point. The two tangents of the curve before the critical point were also drawn, and the deviatoric stress value at the intersection of these two tangents represented the long-term strength of the rock. The relationship between the steady-state creep rate of the tested red sandstone and the applied deviatoric stress at a confining pressure of $2 \mathrm{MPa}$ after different numbers of freeze-thaw cycles was analyzed to determine the long-term strength of the red sandstone, as shown in Figure 19.

When the confining pressure was $2 \mathrm{MPa}$, the long-term strength of red sandstone that did not undergo freeze-thaw cycles was $17.33 \mathrm{MPa}$, and after 1 freeze-thaw cycle, the long-term strength was $17.18 \mathrm{MPa}$, which was $0.92 \%$ lower than that for 0 freeze-thaw cycles. As the number of freezethaw cycles increased, the long-term strength results of the red sandstone were $14.69,13.83$, and $12.36 \mathrm{MPa}$ after 5, 9, and 13 freeze-thaw cycles, respectively, which were $15.23 \%$, $20.19 \%$, and $28.68 \%$ lower than that for 0 freeze-thaw cycles, respectively. The freeze-thaw cycle significantly influenced the long-term strength of the red sandstone. The relationship between the number of freeze-thaw cycles and the long-term strength of the red sandstone was determined to evaluate the effect of freeze-thaw cycles on the long-term strength of this red sandstone (Figure 19). The coefficient of determination $\left(R^{2}\right)$ was 0.9511 , and the fitting equation is expressed in

$$
\sigma_{\infty}=12.2717-0.3796 N
$$

where $\sigma_{\infty}$ represents the creep rate and $N$ represents the number of freeze-thaw cycles.

Figure 20 shows that the long-term strength of the tested red sandstone linearly decreased with an increase in the number of freeze-thaw cycles. This trend was different from previous results, in which the conventional triaxial compressive strength decreased exponentially as the number of freeze-thaw cycles increased. The reason for this difference may be related to the creep damage generated during rock creep. The long-term strength ratio of rock $\lambda$ was proposed to investigate the relationships between the long-term strength and triaxial compressive strength and the effect of the number of freeze-thaw cycles on the long-term strength and triaxial compressive strength. The long-term strength ratio of rock $\lambda$ is defined as the ratio of the long-term strength to the triaxial compressive strength, as expressed in

$$
\lambda=\frac{\sigma_{\infty}}{\sigma_{c}}
$$

The long-term strength ratios of the red sandstone under $2 \mathrm{MPa}$ of confining pressure are shown in Figure 21 for different numbers of freeze-thaw cycles according to the longterm strength and triaxial compressive strength results. The long-term strength ratio increased firstly and then decreased. After 1 freeze-thaw cycle and 13 freeze-thaw cycles, the longterm strength ratios were 0.9 and 0.75 , respectively, and the variations for 1 freeze-thaw cycle and 13 cycles were higher than those for 0,5 , and 9 cycles. This result was attributed to the significant effect of the variation in the rock samples on the long-term strength. Thus, the samples subjected to different freeze-thaw conditions did not experience failure at the same stress level, which remarkably influenced the long-term strength ratio. For example, the rock sample exposed to 1 freeze-thaw cycle failed at the seventh stress level, but the rock sample exposed to 13 freeze-thaw cycles failed at the fifth stress level.

3.6. Red Sandstone Failure Mode after Multilevel Loading and Unloading Creep. Figure 22 shows the creep failure morphology and corresponding sketch of the red sandstone fractures under different confining pressures and freeze-thaw conditions. The confining pressure significantly influenced the creep failure mode of the rock under the same freeze-thaw conditions. The rock exhibited a typical single-shear failure mode and splitting failure mode under confining pressures of 0 and $2 \mathrm{MPa}$, respectively. When the confining pressure was high (4 and $6 \mathrm{MPa}$ ), two or more shear planes formed in the rock, signifying a typical double-shear failure or multiple-shear failure mode. Different degrees of secondary cracking occurred around the rock sample fracture surfaces, mainly when the confining pressure and the number of freeze-thaw cycles were high. At a confining pressure of $6 \mathrm{MPa}$, the rock sample subjected to 0 freeze-thaw cycles was divided into several fragments by multiple oblique shear planes, and the integrity of the rock was disturbed. This tendency to fragment was driven by the continual development and expansion of the structural defects and microcracks inside the rocks, causing damage under repeated loading and unloading and long-term loading during the multilevel loading and unloading creep tests. Multiple cracks were generated at the same time as the main fracture surface was formed. The freeze-thaw cycle had a significant effect on the rock failure mode. When the number of freeze-thaw cycles was high, the rock samples under high confining pressures developed transverse shear planes. The rock fragmented into several pieces by this transverse shear plane and multiple oblique shear planes. The rock samples fragmented more significantly under higher confining pressures and numbers of freeze-thaw cycles, and the integrity of the samples declined sharply.

\section{Conclusion}

In this study, triaxial multilevel loading and unloading creep tests and SEM were performed on red sandstone under different freeze-thaw and confining pressure conditions. The main conclusions are as follows:

The SEM and binarized images show that as the number of freeze-thaw cycles increased, the boundaries of the rock particles became more distinct, and more pores formed.

The effect of freeze-thaw cycles on the creep deformation of red sandstone was related to the stress loading level. At low stress levels, the total creep strain of the rock increased slowly and almost linearly with the number of freeze-thaw cycles; however, at high stress levels, the total creep strain increased 
nonlinearly. The fourth loading stress level $\left(70 \% \sigma_{c}\right)$ corresponded to the transition point of the creep deformation of the tested red sandstone. The change in the viscoelastic strain with the number of freeze-thaw cycles was similar to that of the total creep. However, the viscoplastic strain increased almost linearly with the number of freeze-thaw cycles.

The instantaneous strain increased almost parabolically with the confining pressure. When the confining pressure was low, a higher stress level caused the confining pressure to have a more significant effect on the creep strain. However, as the confining pressure continued to increase, the effect of the confining pressure on the creep strain eventually disappeared.

The steady-state creep rate of the tested rock was significantly influenced by the number of freeze-thaw cycles and confining pressure. The steady-state creep rate of this red sandstone increased exponentially with the number of freeze-thaw cycles at the same confining pressure, but it increased linearly with the increase in confining pressure under similar freeze-thaw conditions.

The long-term strength of the red sandstone decreased nearly linearly with the increase in the number of freezethaw cycles. The long-term strength ratio $\lambda$ of the red sandstone was defined. The long-term strength ratio increased firstly and then decreased under different numbers of freeze-thaw cycles.

The creep failure mode of the red sandstone was significantly influenced by the number of freeze-thaw cycles and the confining pressure. At low confining pressures, the failure mode of the rock was mainly single-shear failure, whereas at high confining pressures, failure mode was mainly doubleshear failure. Repeated loading and unloading and longterm loading resulted in the development of secondary cracks around the rock fracture surfaces. The rock samples formed a transverse shear plane when the number of freeze-thaw cycles and the confining pressure were high, and those rock samples were more fragmented than the rock samples without a transverse shear plane.

\section{Discussion}

In this paper, the concept of long-term strength ratio is put forward, but there was no consistent variation through the change of experimental data. So, if the relationship between the long-term strength ratio and the number of freeze-thaw cycles can be established, then the long-term strength of the rock can be indirectly deduced from the conventional triaxial compressive strength in the freeze-thaw environment. This has significant reference value for construction in rock mass engineering and long-term stability analysis in cold regions. Therefore, the trends of the long-term strength ratios in different freeze-thaw environments need to be investigated further.

\section{Data Availability}

The data supporting the results of our study are included within the manuscript.

\section{Conflicts of Interest}

The authors declare that they have no conflicts of interest.

\section{Acknowledgments}

This study was supported by the National Natural Science Foundation of China (Nos. 11972283, 41702346 and 11872299) and the Natural Science Foundation of Shaanxi Province of China (No. 2017JM1039). The authors are grateful for the generous support.

\section{References}

[1] T. Yamabe and K. M. Neaupane, "Determination of some thermo-mechanical properties of Sirahama sandstone under subzero temperature condition," International Journal of Rock Mechanics and Mining Sciences, vol. 38, no. 7, pp. 1029-1034, 2001.

[2] T. C. Chen, M. R. Yeung, and N. Mori, "Effect of water saturation on deterioration of welded tuff due to freeze-thaw action," Cold Regions Science and Technology, vol. 38, no. 2-3, pp. 127136, 2004.

[3] H. Yavuz, R. Altindag, S. Sarac, S. Ugur, and N. Sengun, "Estimating the index properties of deteriorated carbonate rocks due to freeze-thaw and thermal shock weathering," International Journal of Rock Mechanics and Mining Sciences, vol. 43, no. 5, pp. 767-775, 2006.

[4] H. M. Zhang and G. S. Yang, "Research on damage model of rock under coupling action of freeze-thaw and load," Chinese Journal of Rock Mechanics and Engineering, vol. 29, no. 3, pp. 471-476, 2010.

[5] F. Bayram, "Predicting mechanical strength loss of natural stones after freeze-thaw in cold regions," Cold Regions Science and Technology, vol. 83-84, pp. 98-102, 2012.

[6] G. Khanlari, R. Z. Sahamieh, and Y. Abdilor, "The effect of freeze-thaw cycles on physical and mechanical properties of Upper Red Formation sandstones, central part of Iran," Arabian Journal of Geosciences, vol. 8, no. 8, pp. 5991-6001, 2015.

[7] A. Momeni, Y. Abdilor, G. R. Khanlari, M. Heidari, and A. A. Sepahi, "The effect of freeze-thaw cycles on physical and mechanical properties of granitoid hard rocks," Bulletin of Engineering Geology and the Environment, vol. 75, no. 4, pp. 1649-1656, 2016.

[8] W. Liping, L. Ning, Q. Jilin, T. Yanzhe, and X. Shuanhai, “A study on the physical index change and triaxial compression test of intact hard rock subjected to freeze-thaw cycles," Cold Regions Science and Technology, vol. 160, pp. 39-47, 2019.

[9] S. Z. Seyed Mousavi, H. Tavakoli, P. Moarefvand, and M. Rezaei, "Assessing the effect of freezing-thawing cycles on the results of the triaxial compressive strength test for calcschist rock," International Journal of Rock Mechanics and Mining Sciences, vol. 123, article 104090, 2019.

[10] H. C. Zhao, X. L. Zhang, G. Han, and H. Chen, "Experimental investigation on the physical and mechanical properties deterioration of oil shale subjected to freeze-thaw cycles," Arabian Journal of Geosciences, vol. 12, no. 16, 2019.

[11] Y. Lu, X. Li, and A. Chan, "Damage constitutive model of single flaw sandstone under freeze-thaw and load," Cold Regions Science and Technology, vol. 159, pp. 20-28, 2019. 
[12] K. Peng, J. Q. Zhou, Q. L. Zou, and X. Song, "Effect of loading frequency on the deformation behaviours of sandstones subjected to cyclic loads and its underlying mechanism," International Journal of Fatigue, vol. 131, p. 105349, 2020.

[13] T. Han, J. Shi, and X. Cao, "Fracturing and damage to sandstone under coupling effects of chemical corrosion and freeze-thaw cycles," Rock Mechanics and Rock Engineering, vol. 49, no. 11, pp. 4245-4255, 2016.

[14] J. Ni, Y. L. Chen, P. Wang, S. R. Wang, B. Peng, and R. Azzam, "Effect of chemical erosion and freeze-thaw cycling on the physical and mechanical characteristics of granites," Bulletin of Engineering Geology and the Environment, vol. 76, no. 1, pp. 169-179, 2017.

[15] J. Zhang, H. Deng, A. Taheri, B. Ke, C. Liu, and $\mathrm{X}$. YangDegradation of physical and mechanical properties of sandstone subjected to freeze-thaw cycles and chemical erosion," Cold Regions Science and Technology, vol. 155, pp. 37-46, 2018.

[16] H. L. Jia, S. Ding, F. Zi, Y. Dong, and Y. J. Shen, "Evolution in sandstone pore structures with freeze-thaw cycling and interpretation of damage mechanisms in saturated porous rocks," Catena, vol. 195, article 104915, 2020.

[17] Y. L. Zhao, Y. X. Wang, W. Wang, L. Tang, Q. Liu, and G. Cheng, "Modeling of rheological fracture behavior of rock cracks subjected to hydraulic pressure and far field stresses," Theoretical and Applied Fracture Mechanics, vol. 101, pp. 5966, 2019.

[18] F. I. Shalabi, "FE analysis of time-dependent behavior of tunneling in squeezing ground using two different creep models," Tunnelling and Underground Space Technology, vol. 20, no. 3, pp. 271-279, 2005.

[19] D. Sterpi and G. Gioda, "Visco-plastic behaviour around advancing tunnels in squeezing rock," Rock Mechanics and Rock Engineering, vol. 42, no. 2, pp. 319-339, 2009.

[20] N. Brantut, M. J. Heap, P. G. Meredith, and P. Baud, “Timedependent cracking and brittle creep in crustal rocks: a review," Journal of Structural Geology, vol. 52, pp. 17-43, 2013.

[21] P. Kang, L. Hong, Y. Fazhi, Z. Quanle, S. Xiao, and L. Zhaopeng, "Effects of temperature on mechanical properties of granite under different fracture modes," Engineering Fracture Mechanics, vol. 226, article 106838, 2020.

[22] Y. L. Zhao, L. Y. Zhang, J. Liao, W. J. Wang, Q. Liu, and L. M. Tang, "Experimental study of fracture toughness and subcritical crack growth of three rocks under different environments," International Journal of Geomechanics, vol. 20, no. 8, article 04020128, 2020.

[23] K. Miura, Y. Okui, and H. Horii, "Micromechanics-based prediction of creep failure of hard rock for long-term safety of high-level radioactive waste disposal system," Mechanics of Materials, vol. 35, no. 3-6, pp. 587-601, 2003.

[24] G. Fabre and F. Pellet, "Creep and time-dependent damage in argillaceous rocks," International Journal of Rock Mechanics and Mining Sciences, vol. 43, no. 6, pp. 950-960, 2006.

[25] Y. L. Zhao, C. S. Zhang, Y. X. Wang, and H. Lin, "Shear-related roughness classification and strength model of natural rock joint based on fuzzy comprehensive evaluation," International Journal of Rock Mechanics and Mining Sciences, no. article 104550, 2020.
[26] X. Y. Shang and H. Tkalčić, "Point-source inversion of small and moderate earthquakes from $\mathrm{p}$-wave polarities and $\mathrm{p} / \mathrm{s}$ amplitude ratios within a hierarchical Bayesian framework: implications for the geysers earthquakes," Solid Earth, vol. 125, no. 2, 2020.

[27] P. Cao, L. H. Wan, Y. X. Wang, Y. H. Huang, and X. Y. Zhang, "Viscoelasto-plastic properties of deep hard rocks under water environment," Transactions of Nonferrous Metals Society of China, vol. 21, no. 12, pp. 2711-2718, 2011.

[28] K. Peng, J. Q. Zhou, Q. L. Zou, Y. J. Zhang, and G. W. Tan, "Deformation characteristics and failure modes of sandstones under discontinuous multi-level cyclic loads," Powder Technology, vol. 373, pp. 599-613, 2020.

[29] G. Q. Chen, F. Guo, J. C. Wang, and Y. X. Zhou, "Experimental study of creep properties of quartz sandstone after freezingthawing cycles," Rock and Soil Mechanics, vol. 38, Supplement 1, pp. 203-210, 2017.

[30] X. Yang, A. Jiang, and M. Li, "Experimental investigation of the time-dependent behavior of quartz sandstone and quartzite under the combined effects of chemical erosion and freezethaw cycles," Cold Regions Science and Technology, vol. 161, pp. 51-62, 2019.

[31] X. Li, D. Qu, Y. Luo, R. Ma, K. Xu, and G. Wang, "Damage evolution model of sandstone under coupled chemical solution and freeze-thaw process," Cold Regions Science and Technology, vol. 162, pp. 88-95, 2019.

[32] A. W. Hatheway, "The Complete ISRM Suggested Methods for Rock Characterization, Testing and Monitoring; 1974-2006," Environmental and Engineering Geoence, vol. 15, no. 1, pp. 47-48, 2009.

[33] L. Ma and J. J. K. Daemen, "An experimental study on creep of welded tuff," International Journal of Rock Mechanics and Mining Sciences, vol. 43, no. 2, pp. 282-291, 2006.

[34] Y. Zhao, L. Zhang, W. Wang et al., "Creep behavior of intact and cracked limestone under multi-level loading and unloading cycles," Rock Mechanics and Rock Engineering, vol. 50, no. 6, pp. 1409-1424, 2017.

[35] Y. F. Sun and Y. H. Li, "Experimental study of the influence of moisture content and confining pressure on sandstone creep characteristics," Journal of Experimental Mechanics, vol. 33, no. 1, pp. 159-166, 2018.

[36] W. Chen and F. Zhao, "Triaxial testing study on creep characteristics of mica-quartzose schist," Journal of Engineering Geology, vol. 15, no. 4, pp. 545-548, 2007.

[37] Y. J. Song, L. T. Zhang, H. M. Yang, J. X. Ren, and Y. X. Che, "Experimental study on the creep behavior of red sandstone under low temperatures," Advances in Civil Engineering, vol. 2019, Article ID 2328065, 9 pages, 2019.

[38] C. C. Xia and S. Zhong, "Experimental data processing method in consideration of influence of loading history on rock specimen deformation," Journal of Central South University Science and Technology, vol. 20, no. 1, pp. 18-24, 1989.

[39] H. W. Zhou, H. P. Xie, and J. P. Zuo, "Developments in researches on mechanical behaviors of rocks under the condition of high ground pressure in the depths," Advances in Mechanics, vol. 35, no. 1, pp. 91-99, 2005.

[40] Y. L. Zhao, L. Y. Zhang, W. J. Wang, Q. Liu, L. M. Tang, and G. M. Cheng, "Experimental study on shear behavior and a revised shear strength model for infilled rock joints," 
International Journal of Geomechanics, vol. 20, no. 9, article 04020141, 2020.

[41] K. Peng, Z. P. Liu, Q. L. Zou, Q. H. Wu, and J. Q. Zhou, "Mechanical property of granite from different buried depths under uniaxial compression and dynamic impact: an energybased investigation," Powder Technology, vol. 362, pp. 729$744,2020$.

[42] D. S. Wu, L. B. Meng, T. B. Li, and L. Lai, "Study of triaxial rheological property and long-term strength of limestone after high temperature," Rock and Soil Mechanics, vol. 37, Supplement 1, pp. 183-191, 2016. 